\title{
A Rouse-based method to integrate the chemical composition of river sediments: Application to the Ganga basin
}

\author{
Maarten Lupker, ${ }^{1}$ Christian France-Lanord, ${ }^{1}$ Jérôme Lavé, ${ }^{1}$ Julien Bouchez, ${ }^{2,3}$ \\ Valier Galy, ${ }^{4}$ François Métivier, ${ }^{2}$ Jérôme Gaillardet, ${ }^{2}$ Bruno Lartiges, ${ }^{5}$ \\ and Jean-Louis Mugnier ${ }^{6}$
}

Received 8 December 2010; revised 27 July 2011; accepted 27 July 2011; published 1 November 2011.

[1] The Ganga River is one of the main conveyors of sediments produced by Himalayan erosion. Determining the flux of elements transported through the system is essential to understand the dynamics of the basin. This is hampered by the chemical heterogeneity of sediments observed both in the water column and under variable hydrodynamic conditions. Using Acoustic Doppler Current Profiler (ADCP) acquisitions with sediment depth profile sampling of the Ganga in Bangladesh we build a simple model to derive the annual flux and grain size distributions of the sediments. The model shows that ca. $390( \pm 30) \mathrm{Mt}$ of sediments are transported on average each year through the Ganga at Haring Bridge (Bangladesh). Modeled average sediment grain size parameters $D_{50}$ and $D_{84}$ are $27( \pm 4)$ and $123( \pm 9) \mu \mathrm{m}$, respectively. Grain size parameters are used to infer average chemical compositions of the sediments owing to a strong grain size chemical composition relation. The integrated sediment flux is characterized by low $\mathrm{Al} / \mathrm{Si}$ and $\mathrm{Fe} / \mathrm{Si}$ ratios that are close to those inferred for the Himalayan crust. This implies that only limited sequestration occurs in the Gangetic floodplain. The stored sediment flux is estimated to c.a. $10 \%$ of the initial Himalayan sediment flux by geochemical mass balance. The associated, globally averaged sedimentation rates in the floodplain are found to be ca. $0.08 \mathrm{~mm} / \mathrm{yr}$ and yield average Himalayan erosion rate of ca. $0.9 \mathrm{~mm} / \mathrm{yr}$. This study stresses the need to carefully address the average composition of river sediments before solving large-scale geochemical budgets.

Citation: Lupker, M., C. France-Lanord, J. Lavé, J. Bouchez, V. Galy, F. Métivier, J. Gaillardet, B. Lartiges, and J.-L. Mugnier (2011), A Rouse-based method to integrate the chemical composition of river sediments: Application to the Ganga basin,

J. Geophys. Res., 116, F04012, doi:10.1029/2010JF001947.

\section{Introduction}

[2] Rivers play a central role in Earth's physical and geochemical cycles. They redistribute mass and chemical elements across the earth surface by transporting the products of erosion to the oceans. Large rivers are also powerful basin scale integrators of the geochemical and physical continental processes [Holeman, 1968; Martin and Meybeck, 1979; Viers et al., 2009]. The analysis of suspended sediments carried by rivers is of prime importance as they provide insights into the physical denudation rates in the basin [e.g., Milliman and Meade, 1983] and the recycling of continental crust [e.g., Taylor and McLennan, 1985; Goldstein and Jacobsen, 1988]. Moreover, suspended sediments are complementary tracers to river-dissolved fluxes of continental silicate weathering

\footnotetext{
${ }^{1}$ CRPG-CNRS, Vandœuvre lès Nancy, France.

${ }^{2} \mathrm{IPG}$, Paris, France.

${ }^{3}$ GFZ-Helmholtz Zentrum Potsdam, Potsdam, Germany.

${ }^{4}$ Department of Marine Chemistry and Geochemistry, Woods Hole

Oceanographic Institution, Woods Hole, Massachusetts, USA.

${ }^{5}$ LEM, Vandœuvre lès Nancy, France.

${ }^{6}$ ISTerre, Saint-Martin D'Hères, France.

Copyright 2011 by the American Geophysical Union. 0148-0227/11/2010JF001947
}

rates and organic carbon burial [e.g., France-Lanord and Derry, 1997; Gaillardet et al., 1999; Gislason et al., 2006; Galy et al., 2007].

[3] This work is an attempt to evaluate the average chemical composition of the sediments transported by the Ganga fluvial system (Figure 1). Ganga is one of the three main conveyors, with the Indus and the Brahmaputra, of the material eroded within Himalayan catchments and assessing the total flux of eroded material is crucial for the understanding of physical processes governing mountain growth and erosion [e.g., Willett, 1999; Avouac and Burov, 1996; Beaumont et al., 2001; Hodges et al., 2001]. The determination of the chemical composition of this eroded material is also important to quantify sedimentary and chemical budgets at the continental scale and to specify the role of Himalayan tectonics in the global long-term carbon cycle [e.g., Raymo et al., 1988; Edmond, 1992; France-Lanord and Derry, 1997; Galy and France-Lanord, 2001; Galy et al., 2007].

[4] Very few studies have tried to assess the integrated annual composition of the sediments transported to the oceans. The mean chemical composition of large river sediments is often estimated through simple averaging of available data [e.g., Martin and Meybeck, 1979; Viers et al., 2009 , and references therein], which is highly dependent on 


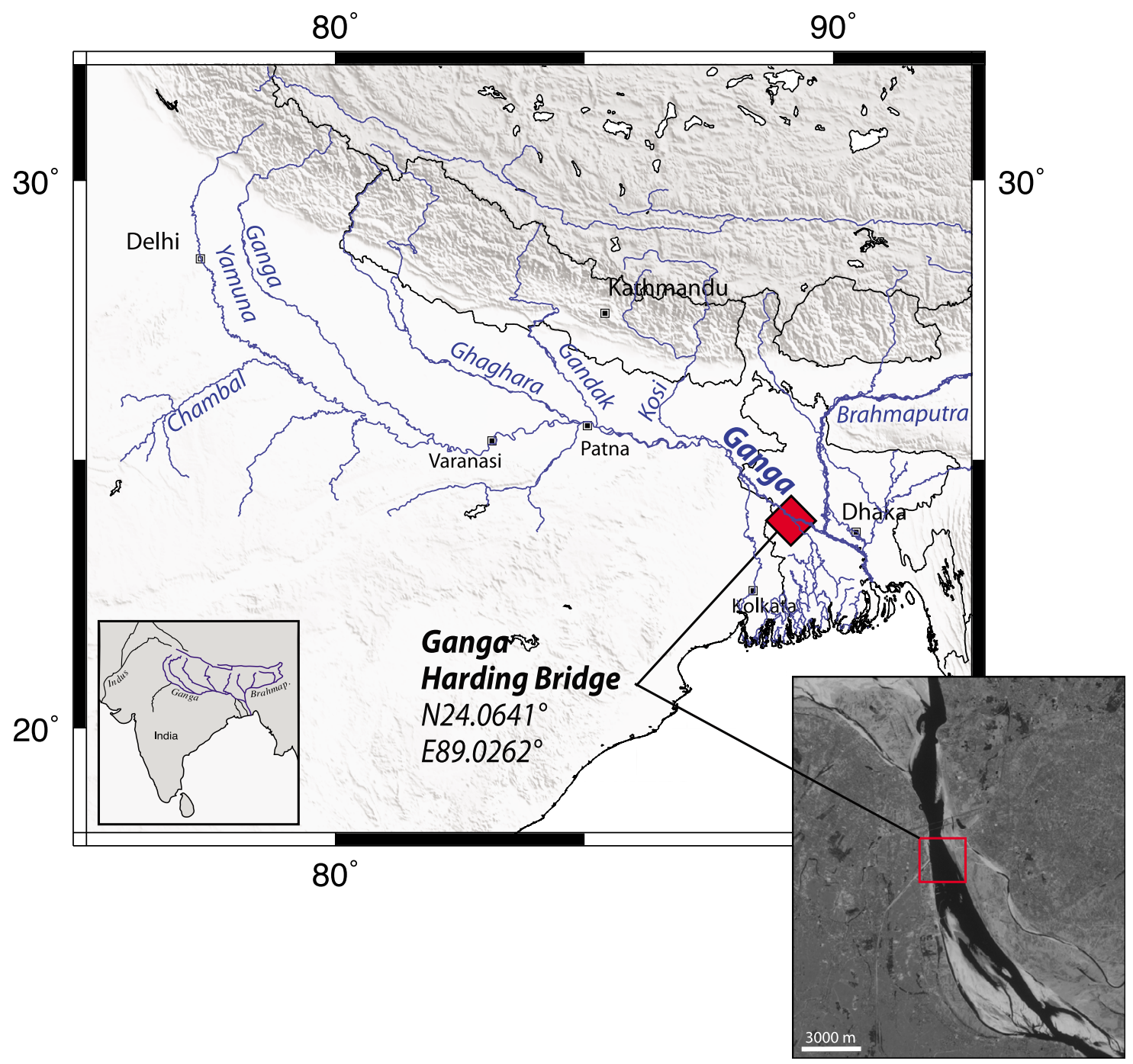

Figure 1. Hydrological setting of the Ganga basin and Landsat image of the sampling zone. River sediment depth samplings were performed during monsoon 2002, 2004, 2005, 2007, 2008 and 2010 on the Ganga downstream of Harding Bridge in Bangladesh.

sampling quality and strategy. The lack of knowledge of the exported chemical flux can be attributed to the difficulty to spatially and temporally average highly heterogeneous properties such as the sediments' composition in a given large river channel. Since it has been recognized that surface samples are not representative of the whole water column [e.g., Curtis et al., 1979] several studies have used depthsampling methods to reveal spatial variability in sediment characteristics such as grain-size and chemical composition [e.g., Horowitz and Elrick, 1987; Singh and France-Lanord, 2002; Filizola and Guyot, 2004; Galy et al., 2007; Bouchez et al., 2010, 2011a, 2011b, 2011c]. This variability is the result of hydrodynamic sorting through the combined effect of downward settling forces and upward turbulent forces exerted on the sediments which tends to enrich the bottom of the water column in coarse sediments while the surface is enriched in fine material.

[5] Building upon classical principles of suspension and transport we attempt to model the average grain size of the Ganga river sediment fluxes. The average grain size is then used to infer the chemical composition of the Ganga sediment flux and can be further used in geochemical budgets. Our approach is based on detailed sampling of Ganga sediments through the water column during monsoon season under variable river stage, combined with water velocity measurements.

\section{Sampling Strategy and Analytical Methods}

\subsection{The Ganga Fluvial System}

[6] The headwaters of the Ganga basin are mainly composed of major trans-Himalayan Rivers that produce most of the sediment load in the system. These rivers drain the four main geological units that extend along the entire Himalayan arc (from North to South: the Cambrian to Eocene marine sedimentary rocks of the Tethyan Sedimentary Series, TSS; schist and gneiss of the High Himalaya Crystalines, HHC; low-grade meta-sediments of the Lesser Himalaya, LH; and Tertiary molasse deposits of the Siwaliks [cf. Gansser, 1964; Le Fort, 1975]). After more than $1000 \mathrm{~km}$ of transit through 


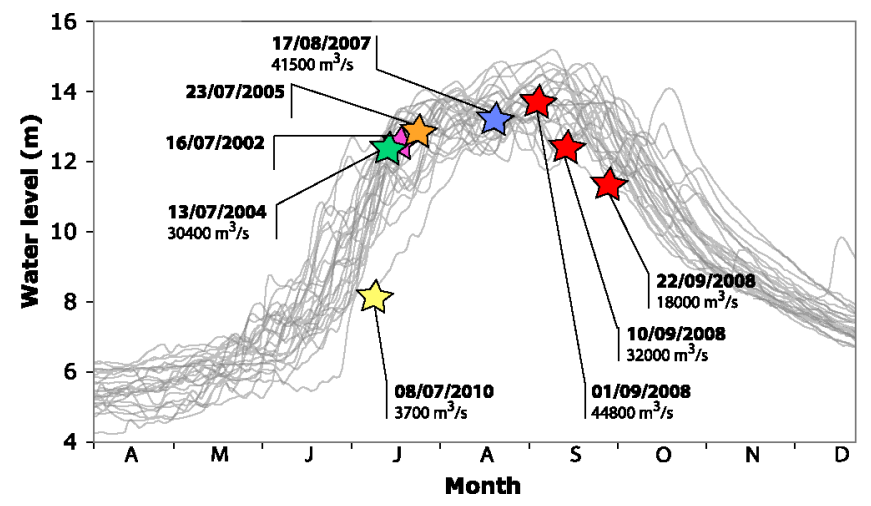

Figure 2. Hydrographs of the Ganga at Harding Bridge (Bangladesh) from 1980 to 2004 for the months of April to December (Bangladesh Water Development Board data). Average arrival and withdrawal dates of the summer monsoon over Bangladesh are 10th of June to the 8th of October, respectively [Ahmed and Karmakar, 1993]. Stars mark sampling dates and respective gauged water height of the Ganga. Measured ADCP water discharges are indicated when full transects were performed.

the Indo-Gangetic floodplain, the Ganga merges with the Brahmaputra in Bangladesh, to form the lower Meghna that flows into the Bay of Bengal. The Indo-Gangetic floodplain is the surface of a foreland flexural basin developed at the Himalayan subduction front and is filled by several kilometers of sediments eroded from the Himalayan range [LyonCaen and Molnar, 1985]. In the floodplain, the Ganga also receives contributions from rivers draining the Indian shield to the south of the Indo-Gangetic plain and part of the Deccan traps. The total drainage area of the Ganga covers 1.06 million $\mathrm{km}^{2}$ of which $17 \%$ lies in the Himalaya, $35 \%$ in the Indian shield and $48 \%$ the Ganga plain [Rao, 1979].

[7] The annual water discharge of the Ganga in Bangladesh (Harding Bridge) varies between 270 and $460 \mathrm{~km}^{3} / \mathrm{yr}$ with an average value of $352 \mathrm{~km}^{3} / \mathrm{yr}$ according to the Bangladesh Flood Forecasting and Warning Center (FFWC) and Water Resources Planning Organization (WARPO) hydrological data. The hydrograph is strongly influenced by monsoonal rainfalls (June-September), which account for most of the discharge. About $54 \%$ of the Ganga total discharge is derived from Himalayan catchments where precipitation is enhanced due to orographic effects while southern tributaries account only for $22 \%$ of the total discharge [Rao, 1979; Singh et al., 2008]. Sediment flux follows a pattern similar to that of discharge but with $95 \%$ of the suspended matter flux being transported during the monsoon period [Delft Hydraulics and Danish Hydraulics Institute, 1996; Islam et al., 1999; Islam and Jaman, 2006].

[8] In order to document sediment quality and chemical composition as a function of hydrodynamic conditions, water velocity measurements and sediment sampling were performed on the Ganga in Bangladesh during the monsoon in 2002, 2004, 2005, 2007, 2008 and 2010. The section sampled is located immediately downstream of Harding Bridge $\left(\mathrm{N} 24.0641^{\circ}, \mathrm{E} 89.0262^{\circ}\right)$ near the Flood Forecasting and Warning Center hydrological station \#90 (detailed map can be found in Figure A1). This section integrates all tributaries of the Ganga and is located ca. $80 \mathrm{~km}$ upstream of the confluence with the Brahmaputra (Figure 1). Depending on the water level, the width of the river ranged from 1 to $2 \mathrm{~km}$ and maximum depth reached $20 \mathrm{~m}$.

\subsection{ADCP Data Acquisition}

[9] The velocity distribution in the water column was measured continuously during sediment sampling, except for the 2002 campaign, using Acoustic Doppler Current Profiling (ADCP: Rio Grande, RD Instruments, $1200 \mathrm{kHz}$ ) mounted to the side of the boat [e.g., Filizola and Guyot, 2004; Muste et al., 2004]. Velocity measurements were acquired every 1 to $2 \mathrm{~s}$ with a vertical resolution or bin size of 0.25 to $2 \mathrm{~m}$ depending on the instrument's configuration. Additionally, full river transects were recorded by crossing the river normal to the flow to measure total water discharge. During the 2007, 2008 and 2010 campaigns a GPS was used in combination with the ADCP to correct for possible moving bed bias. Moving bed bias occurs when the bottom detected by the ADCP is mobile, which tends to under-estimate the absolute water velocities [Callède et al., 2000; Muste et al., 2004; Kostaschuk et al., 2005; Gaeuman and Jacobson, 2006; Mueller and Wagner, 2007]. Before 2007, the velocity data were corrected for this bias. The correction is detailed in section (3.1.1). In 2010 the addition of a depth sounder (Tritech PA200) increased the bottom detection precision and improved the overall data quality.

\subsection{Sediment Sampling}

[10] Sampling was done near the deepest part of the main channel where water velocities are the highest. In 2005 an additional lateral sampling was done under slower water velocities (2005b), and in 2008 the Ganga was sampled 3 times, during yearly maximum discharge (2008a) and 15 and 30 days later, during falling water level (2008b and $2008 \mathrm{c}$, respectively). Although the sampling was systematically performed during the monsoon, the different sampling campaigns cover very contrasted hydrological regimes with discharges ranging from 3700 to $44800 \mathrm{~m}^{3} / \mathrm{s}$, the later being close to maximum daily discharge of the Ganga (Figure 2). Part of this sampling has already been used to estimate the flux and fate of particle organic carbon in the Himalayan basin [Galy et al., 2007, 2008a, 2008b], to infer sediment transfer times using U-series disequilibrium [Granet et al., 2010], to study mineralogical segregation in the water column [Garzanti et al., 2011]. 
[11] Sediments were sampled at different depth in the water column for a single location and day. From a local boat, the point sampler was lowered while the engine was shut off allowing the boat to drift with the current during the time needed to recover the sample. The boat was repositioned to its original position before acquiring the next sample and this procedure was repeated until the whole water column had been sampled adequately (Figure A1). Great care was taken to reposition the boat to the same location between each sample. These procedures were adopted for practical reasons even though it does not allow capturing the instantaneous sediment concentration distribution in the whole water column.

[12] The sampler used during the 2007, 2008 and 2010 campaigns is a horizontal Niskin type bottle comparable to those used on the Amazon by Filizola and Guyot [2004] and Bouchez et al. [2010]. It allows sampling of an approximate volume of ca. $5 \mathrm{~L}$ of water and consists of a plastic tube (id: $\sim 14 \mathrm{~cm}, \mathrm{~L}: \sim 40 \mathrm{~cm}$ ) open at both extremities and mounted on an aluminum frame. A weight of $20 \mathrm{~kg}$ is attached below the frame and a fin ensures that the sampler tube is kept horizontal and parallel to the streamlines. A pressure transducer attached to the frame of the sampler monitors its relative depth. Once the desired depth is reached both doors of the sampler are closed simultaneously using pneumatic actuators and the sampler is lifted back onboard. The sample is then transferred in a plastic container, paying attention to recover any particles left in the sampler. Prior to 2007 sampling was performed using a vertical bottle sampler that was submerged and opened at the desired depth. Comparative tests showed that both method yield similar samples.

[13] Additionally, sediments were sampled with greater vertical resolution near the bottom, at various places in the river channel in 2007 and 2008 to document near bottom suspended sediments. These samples were acquired using a triple sampler consisting of 3 horizontal 1L Niskin type bottles spaced by $0.5 \mathrm{~m}$ and all mounted on a rigid frame. The bottles are pneumatically closed when the sampling device hits the bottom, allowing sampling of suspended sediments at ca. 10,60 and $110 \mathrm{~cm}$ above the bottom.

[14] Finally, bottom sediments ("Bedload": BL) were also dredged, when possible, at the same location as the vertical suspended load profiles using ca. $15 \mathrm{~cm}$ i.d. stainless steel tube that was lowered to the riverbed.

\subsection{Chemical and Grain Size Analysis}

[15] Within 12 to $48 \mathrm{~h}$ of collection, the sediment samples were first weighed and then filtered through $0.22 \mu \mathrm{m}, 90 \mathrm{~mm}$ $ø$, Poly Ether Sulphone (PES) filters in a pressurized Teflon coated filtration unit. Until 2007 the sediments were removed from the filter using small amounts of pre-filtered river water and the sediment-water mixture was stored in tinted borosilicate bottles. In the lab these bottles were decanted during several days, the supernatant pipetted out and the remaining sediments dried at $50^{\circ} \mathrm{C}$ before being weighted. After 2007 the filters with sediments were stored in airtight polyethylene sample bags. In the lab the sediments were freeze-dried before being separated from the filter and weighted. No difference in chemical composition, grain-size or aspect was observed between the two methods described above. After drying, the sediments were gently disaggregated in an agate mortar, avoiding crushing and hence changing the grain size of the sample. During all these steps special care was taken to avoid any loss of material. The sediment concentration was computed by dividing the dried sediment weight by the corresponding amount of water recovered by the sampler.

[16] Major and trace element concentrations were measured by ICP-AES and ICP-MS at Service d'Analyze des Roches et des Minéraux (SARM - CRPG, Nancy-France) on bulk aliquots of $\sim 100 \mathrm{mg}$ of sediment after lithium metaborate fusion [Govindaraju and Mevelle, 1987; Carignan et al., 2001]. Relative uncertainty for major elemental concentration is better than $2 \%$. Calcite and dolomite content of the samples were measured manometrically on $\mathrm{CO}_{2}$ released by $\mathrm{H}_{3} \mathrm{PO}_{4}$ digestion of the bulk sample [McCrea, 1950; Galy et al., 1999].

[17] Grain size analyses of the Ganga samples were performed at Laboratoire Environnement et Minéralurgie (LEM, Nancy-France) with laser diffraction sizers (Malvern Mastersizer and Sympathec Helos). Controlled ultrasonification achieved full disaggregation of the sample before analysis. Repeated analysis of identical sediment samples showed analytical reproducibility better than $10 \%$ on the modal grain size. We note that diffraction devices do not record any shape information of the particles making them poor predictors of settling velocities [McCave et al., 2006]. This does not change the conclusions of this work but should be kept in mind for further comparison.

\section{Results}

\subsection{ADCP Measurements}

\subsubsection{Correction for Moving Bed Bias}

[18] By comparing water velocities measured simultaneously, referenced to the bottom (BT mode) and to the GPS position (GPS mode) it is possible to infer the velocity of the moving bottom layer: $v_{B L}=v_{G P S}-v_{B T}$ [Callède et al., 2000; Rennie et al., 2002; Rennie and Villard, 2004]. ADCP data acquired in 2008 and 2010 shows that for large discharges and high water velocities, the bottom detected by the ADCP is moving (Figure 3). For depth-averaged water velocity smaller than $1.1 \mathrm{~m} / \mathrm{s}$ no significant moving bed was detected but above this threshold the measured velocities in GPS mode are significantly higher than in BT mode showing that the detected bottom was moving. This apparent moving bed was estimated here to correspond to incipient sheet flow bed load transport (see Appendix B) and reaches up to 1.5 to $2 \mathrm{~m} / \mathrm{s}$. The empirical relation between depth-averaged velocity in BT and GPS modes deduced from the 2008 and 2010 ADCP data was used to correct ADCP data for which no GPS was used. This correction is significant for high water levels and leads to a $40 \%$ discharge underestimation if neglected.

\subsubsection{River Velocity Profiles and Discharge}

[19] Ganga water local velocities reach $4 \mathrm{~m} / \mathrm{s}$ during peak flood (2008a) and drop to less than $1 \mathrm{~m} / \mathrm{s}$ at lower water levels (2008c and 2010) (Figure 4). Our discharge measurements and samplings cover most monsoon stages of the hygrograph (Figure 2), from rising water level to peak flood and falling water level. The maximum discharge of the Ganga was measured during august 2008 with a modulus of $44800 \mathrm{~m}^{3} / \mathrm{s}$ for a gauged water level of $13.8 \mathrm{~m}$, consistent with the $\sim 4600 \mathrm{~m}^{3} / \mathrm{s}$ discharge deduced from the Bangladesh Water 


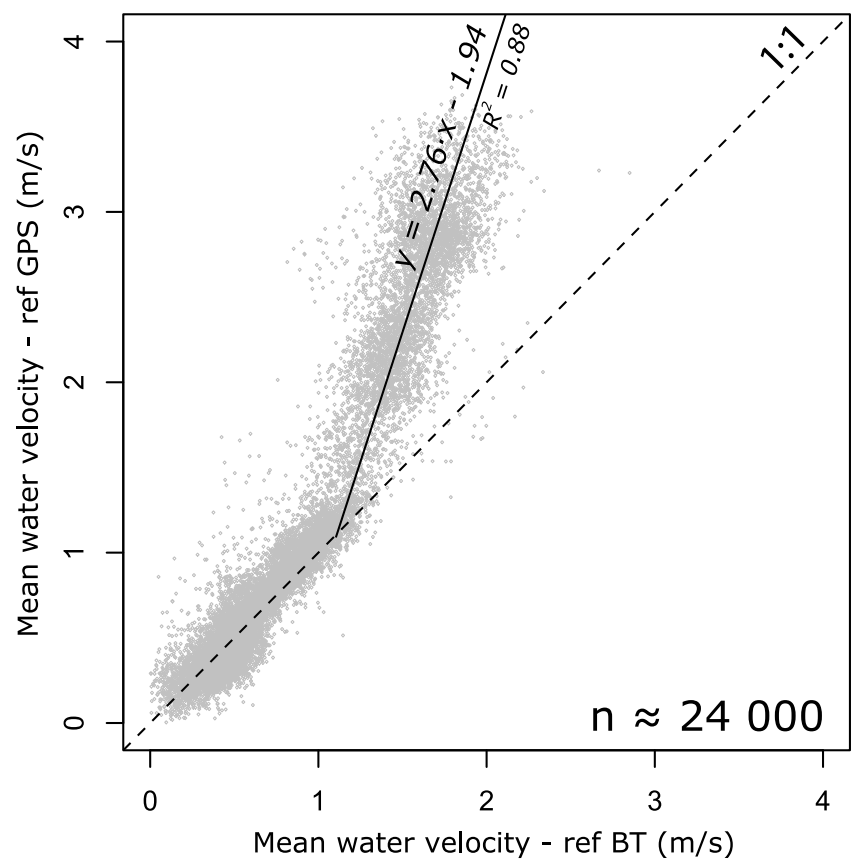

Figure 3. Water column mean velocity as measured simultaneously from bottom tracking mode (BT) of the ADCP (assuming fixed river bottom) and from GPS mode (GPS position as reference). These two modes yield similar results up to $\sim 1.1 \mathrm{~m} / \mathrm{s}$ but diverge for higher water velocities. For higher water velocities significant bed motion is detected. This result can be used to correct measurements where GPS data are not available and that would otherwise be biased toward significantly lower water velocities. These data were generated from $\sim 24000$ vertical velocity profiles (ensembles) acquired on the Ganga in 2008 and 2010.

Development Board (BWDB) rating curve for the same water level.

\subsubsection{Vertical Velocity Profiles}

[20] ADCP measurements were used to document the local hydrodynamic conditions that prevailed during sediment sampling. To avoid the influence of local perturbations, the ADCP signal was averaged over 30 ensembles ( 40 to $70 \mathrm{~m}$ ) to obtain a representative velocity profile for each sediment sample. A composite vertical velocity profile was then produced by stacking the individual velocity profiles of all samples composing the vertical profile (Figure 5 and Table S1 in the auxiliary material). ${ }^{1}$ The uncertainty is propagated from the standard deviation of all ensembles used for a sampled vertical profile and the uncertainty in the moving bed correction when applicable (see section 3.1.1).

[21] The hydrodynamic conditions prevailing during sampling can be determined through the shear velocity $\left(u^{*}\right)$ of the water column. Shear velocity is linked to the basal shear stress $\tau_{0}$ through $u^{*}=\left(\tau_{0} / \rho\right)^{1 / 2}$, with $\rho$ the fluid density. Here, $u^{*}$ is derived from the depth-average velocity $\bar{u}$ following equation (1) [Wilcock, 1996], which was shown to yield a more precise estimation of $u^{*}$ from $\mathrm{ADCP}$ velocity data

\footnotetext{
${ }^{1}$ Auxiliary materials are available in the HTML. doi:10.1029/ $2010 J F 001947$.
}

than unconstrained law of the wall fitting algorithms [Sime et al., 2007]:

$$
u^{*}=\frac{\bar{u} \cdot \kappa}{\ln \left(\frac{H}{e \cdot z_{0}}\right)}
$$

with $\kappa$ the von Karman constant (taken as 0.41 , Garcia [2008]), $H$ the water depth (m) and $e$ the base of the natural logarithms and $z_{0}$ the bottom grain-scale roughness. $\bar{u}$ is derived by fitting and integrating a power law over the velocity profile. A bed roughness of $z_{0}=0.1 \cdot D_{84}=3.10^{-5} \mathrm{~m}$ was used for this work based on average grain size of the dredged bed load samples [Whiting and Dietrich, 1990; Sime et al., 2007]. The measured depth-averaged velocities range from $0.5 \mathrm{~m} / \mathrm{s}(08 / 07 / 2010)$ to $2.7 \mathrm{~m} / \mathrm{s}(17 / 08 / 2007)$ which yields shear velocities from 0.017 to $0.09 \mathrm{~m} / \mathrm{s}$, respectively (Table 1) covering a large range of hydrodynamic conditions.

[22] By using (1) and the $z_{0}$ imposed by bed load grain size, we implicitly formulate that bed shear stress originates from grain scale roughness only, neglecting eventual bed form roughness. The Simons and Richardson [1966] diagram suggests that the high flow profiles mainly occur over an upper plane type of bed. Furthermore, no evidence of large bed forms was imaged by the ADCP (even if the ADCP beams are oriented at $20^{\circ}$ from the vertical and average the bottom depth over ca. $25 \mathrm{~m}^{2}$ for a $10 \mathrm{~m}$ water depth) or by the depth sounder used in 2010. Including bed form roughness would also lead to unrealistic $u^{*}$ and water surface slope to be able to reproduce the measured water column velocity. We however recognize that further high resolution imaging of the river bottom would be required to fully answer the bed form question, but so far no direct evidence of these effects have been found in our data. This observation does also not preclude the occurrence of bed forms in other less constricted reaches of the Ganga.

\subsection{Suspended Load}

\subsubsection{Sediment Concentrations and Grain Size}

[23] Total sediment concentrations are given in Table 2. Among the different profiles, the sediment concentration is highly variable between 0.14 and $3.08 \mathrm{~g} .1^{-1}$ with a mean value of $1.25 \mathrm{~g} .1^{-1}$. A systematic increase in sediment concentration toward the bottom is observed for all profiles with concentrations near the bottom 2 to 3 times higher than the surface. Sediment concentration at the surface varies from $0.14 \mathrm{~g} .1^{-1}$ (2010) to $0.94 \mathrm{~g} . \mathrm{l}^{-1}$ (2005a) while for the deepest samples it varies from $0.24 \mathrm{~g} . \mathrm{l}^{-1}$ (2008c) to $3.3 \mathrm{~g} . \mathrm{l}^{-1}$ (2007). Comparison of $2005 \mathrm{a}$ central profile with lateral profile 2005 b, where velocities are lower, shows limited contrast of concentration except for the deeper sample level. Profiles 2008a, b, c show a decrease in sediment concentration during the fall of water level and discharge with particularly low sediment concentration for 2008c. Sediments sampled using the triple sampler show that concentrations increase in the near bottom region and reach values up to $6.55 \mathrm{~g} / \mathrm{l}^{-1}$.

[24] Ganga suspended sediments are poorly sorted, with an average mode of $22 \mu \mathrm{m}$ and a maximum grain size of $370 \mu \mathrm{m}$. The grain size mode is increasing from surface to bottom sediments and varies in the range of 7 to $109 \mu \mathrm{m}$. Other grainsize parameters such as $D_{84}$ or $D_{90}$ (grain size under which 


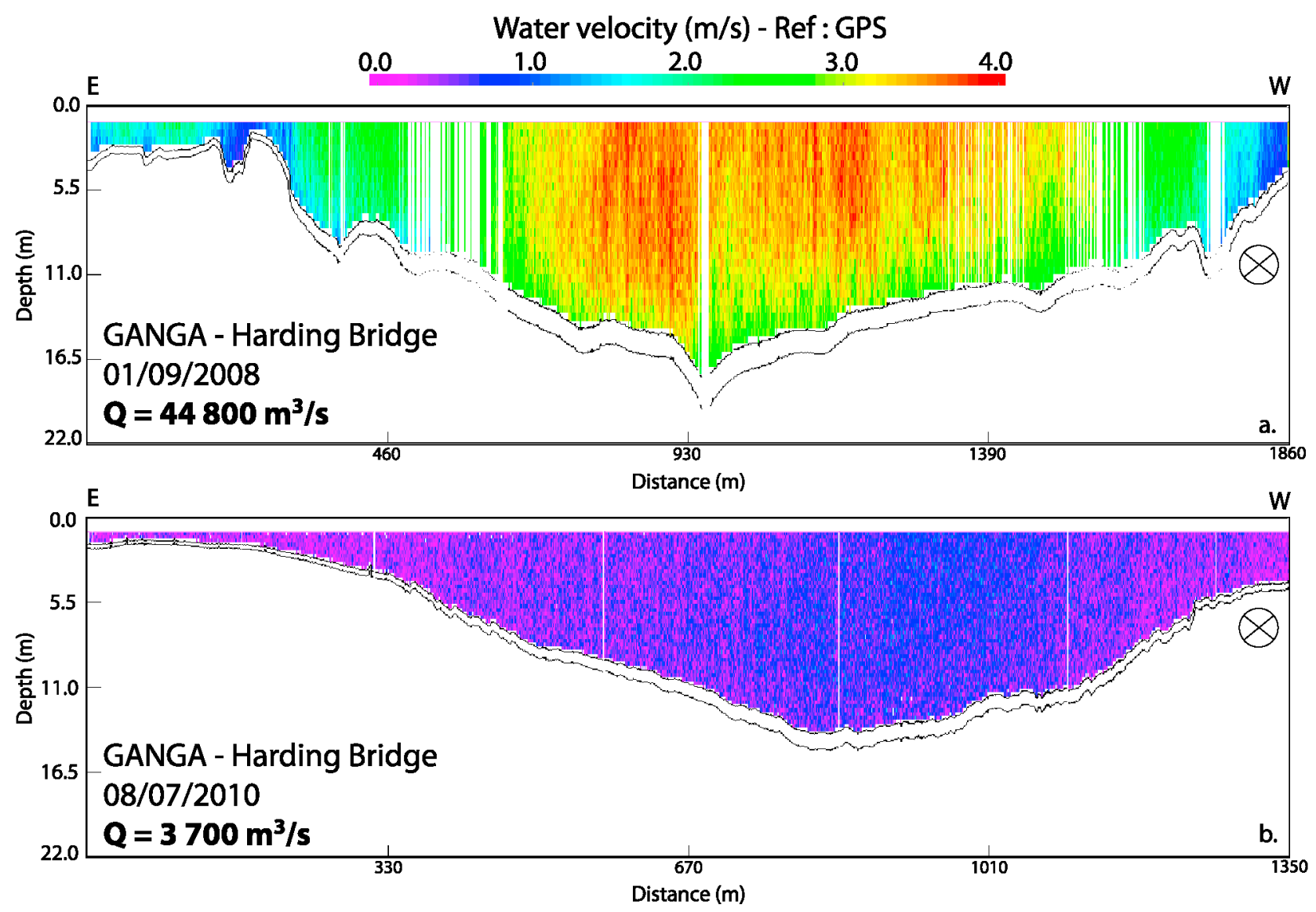

Figure 4. Water velocity distribution of the Ganga at Harding Bridge. Velocity was acquired with an ADCP mounted on the side of the boat and referenced to the GPS position. (a) Ganga section of 01/09/ 2008 during high flow with maximum velocities over $4 \mathrm{~m} / \mathrm{s}$. Measured discharge was $44800 \mathrm{~m}^{3} / \mathrm{s}$. (b) Ganga section of $08 / 07 / 2010$ during low flow conditions (velocity $<1.5 \mathrm{~m} / \mathrm{s}$ ). Measured discharge was $3700 \mathrm{~m}^{3} / \mathrm{s}$.

respectively $84 \%$ and $90 \%$ of the sample volume is distributed) (Table 2) show a similar trend with depth, indicating the predominance of coarser particles near the river bed (Figure 6). Grain size distributions are predominantly unimodal at the surface and tend to become bi-modal close to the riverbed. The fine fraction $(<4 \mu \mathrm{m})$ reaches $20-30 \%$ (by volume) in surface samples and decreases to $6-10 \%$ in bottom sediments while the silt mode $(4-63 \mu \mathrm{m})$ decreases from $60-70 \%$ to $30-40 \%$ close to the bottom. The sand fraction in sediments close to the bed reaches $60 \%$ but drops to $4-7 \%$ in surface sediments.

[25] Dredged sediments have an average $D_{50}$ of $222( \pm 38) \mu \mathrm{m}$ with $D_{84}$ and $D_{90}$ reaching $314( \pm 39)$ and $358( \pm 44) \mu \mathrm{m}$ respectively. They are mainly composed of fine to medium sand with clay $(<4 \mu \mathrm{m})$ and silt $(2-63 \mu \mathrm{m})$ fractions representing less than $0.2 \%$ and $2.5 \%$ of the total sample, respectively. The complete grain-size distribution of samples used in this study can be found in the auxiliary material (Table S2).

3.2.2. Chemical Composition and Grain Size Relations

[26] The complete chemical composition for major and trace elements of samples used in this study is reported in the auxiliary material (Table S3). Sediments at Harding Bridge are dominated by three major elements: silicon ( 52 to $\left.81 \mathrm{wt} \% \mathrm{SiO}_{2}\right)$, aluminum (2 to $8 \mathrm{wt} \% \mathrm{Al}_{2} \mathrm{O}_{3}$ ) and iron (7 to $20 \mathrm{wt} \% \mathrm{Fe}_{2} \mathrm{O}_{3}$ ). Other major element concentrations vary from $3.6( \pm 0.8) \mathrm{wt} \%$ for $\mathrm{CaO}$ to less than $1 \mathrm{wt} \%$ for $\mathrm{MnO}$. Carbonate content of sediments is dominated by both calcite with $3.9( \pm 0.9) \mathrm{wt} \%$ and dolomite with $2.5( \pm 0.4) \mathrm{wt} \%$, which account for respectively $80 \%$ and $28 \%$ of the total $\mathrm{Ca}$ and $\mathrm{Mg}$ content of the sediment. Most major elements show strong relations between grain-size and chemical composition (Figure 7). Partitioning of chemical elements between grainsize classes in river and oceanic sediments has already been observed [e.g., Horowitz and Elrick, 1987; Vdović et al., 1991; Singh et al., 1999; Bouchez et al., 2011b] but here we link sample bulk grain size parameters to chemical elements concentrations. $\mathrm{SiO}_{2}$ and $\mathrm{Na}_{2} \mathrm{O}$ concentrations increase bottomward and are positively correlated to $D_{84}$ while $\mathrm{Al}_{2} \mathrm{O}_{3}$, $\mathrm{Fe}_{2} \mathrm{O}_{3}, \mathrm{MgO}$, and $\mathrm{K}_{2} \mathrm{O}$ concentrations decrease bottomward and are negatively correlated to $D_{84}$. A log linear fit between $D_{84}$ and the chemical composition of the sediments yields correlation coefficients $\mathrm{R}^{2}>0.8$. For $\mathrm{SiO}_{2}$, fitting a third order polynomial law improved the correlation significantly and was preferred over a log law with respect to the use of this element in geochemical mass balance calculations. $D_{84}$ was preferably used over other grain size parameters as smaller grain size parameters such as $D_{50}$ were less 

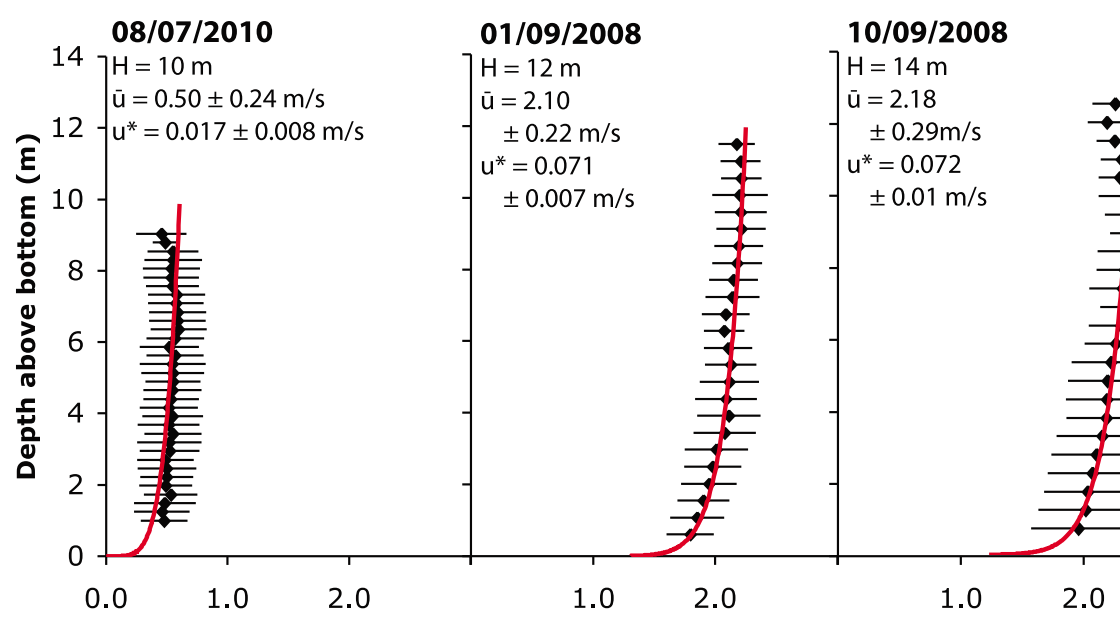

$23 / 07 / 2005$ (b)

$17 / 08 / 2007$

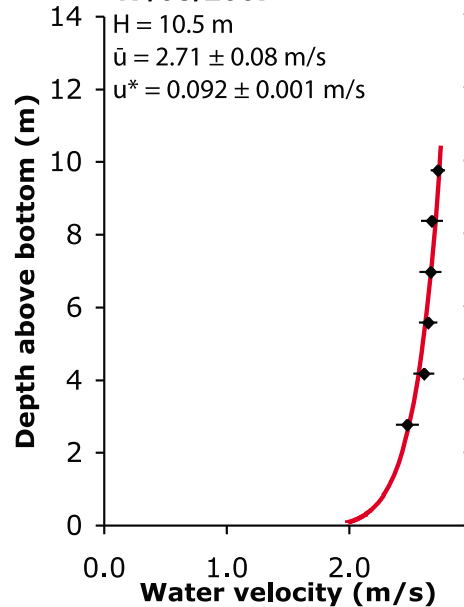

$23 / 07 / 2005$ (a)

$\mathrm{H}=12.5 \mathrm{~m}$

$\overline{\mathrm{u}}=2.13$

$\pm 0.30 \mathrm{~m} / \mathrm{s}$

$u^{*}=0.071$
$\pm 0.01 \mathrm{~m} / \mathrm{s}$

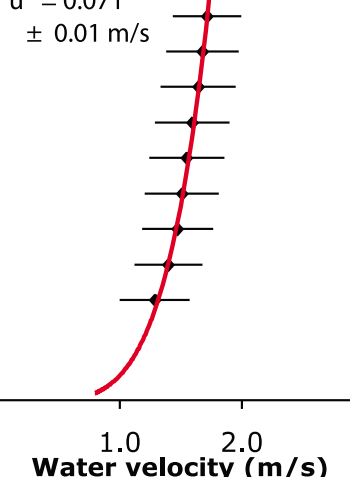

$\mathrm{H}=11 \mathrm{~m}$

$u^{*}=0.034 \pm 0.004 \mathrm{~m} / \mathrm{s}$

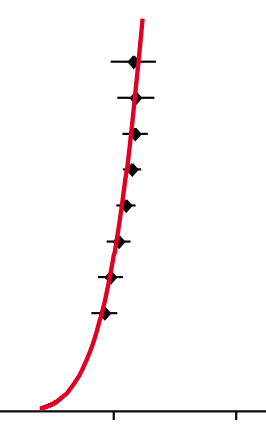

Water velocity $(\mathrm{m} / \mathrm{s})$ $\overline{\mathrm{u}}=1.02 \pm 0.12 \mathrm{~m} / \mathrm{s}$
$22 / 09 / 2008$

$\mathrm{H}=13 \mathrm{~m}$

$\overline{\mathrm{u}}=1.08$

$\pm 0.15 \mathrm{~m} / \mathrm{s}$

$\mathrm{u}^{*}=0.036$

$\pm 0.005 \mathrm{~m} / \mathrm{s}$

Figure 5. Composite velocity profiles of the sampled water columns of the Ganga at Harding Bridge. Velocity profiles are derived from ADCP measurements performed during sampling and allowed the calculation of the average water column velocities $(\bar{u})$ and the shear velocity $\left(u^{*}\right)$. Uncertainties are propagated from uncertainty in velocity measurements and when applicable from uncertainty in moving bed correction (2004 and 2005).

discriminable while higher grain size parameters such as $D_{90}$ were subject to higher uncertainty during sediment transport modeling and grain size analysis. Calcite and dolomite content, but also $\mathrm{CaO}$ and $\mathrm{MnO}$, do not show any simple relation to sample grain size or sampling depth. The notable presence of carbonates dilutes the mono-elemental/grain-size relationships and introduces additional variability. Using elemental ratios such as $\mathrm{Al} / \mathrm{Si}$ or $\mathrm{Fe} / \mathrm{Si}$, which are not affected by carbonate content, improves the overall relations (Figure 7).

[27] Concerning trace elements in the suspended load: As, $\mathrm{Ba}, \mathrm{Bi}, \mathrm{Co}, \mathrm{Cr}, \mathrm{Cs}, \mathrm{Cu}, \mathrm{Ga}, \mathrm{Rb}, \mathrm{V}$ and $\mathrm{Zn}$ concentrations are negatively correlated to $D_{84}$ and higher in the suspended load compared to bed load samples. Be, Eu, Hf, $\mathrm{Nb}, \mathrm{Zr}$ are enriched in the bed load and their concentration in the water

Table 1. Depth and Depth Averaged Velocity of the Sampling Verticals Computed From ADCP Velocity Data ${ }^{\mathrm{a}}$

\begin{tabular}{|c|c|c|c|c|c|c|c|}
\hline Sampling Date & $\begin{array}{l}\text { Depth } \\
\text { (m) }\end{array}$ & $\begin{array}{c}u \text { ADCP } \\
(\mathrm{m} / \mathrm{s})\end{array}$ & $\begin{array}{c}u^{*} \mathrm{ADCP} \\
(\mathrm{m} / \mathrm{s})\end{array}$ & $\begin{array}{l}D_{50} \\
(\mu \mathrm{m})\end{array}$ & $\begin{array}{l}D_{84} \\
(\mu \mathrm{m})\end{array}$ & $\begin{array}{c}q_{s} \\
(\mathrm{~kg} / \mathrm{m} / \mathrm{s})\end{array}$ & $\begin{array}{c}q_{b} \\
(\mathrm{~kg} / \mathrm{m} / \mathrm{s})\end{array}$ \\
\hline $13 / 08 / 10$ & 10.0 & $0.50( \pm 0.24)$ & $0.017( \pm 0.008)$ & 7 & 21 & 0.89 & 0.002 \\
\hline $01 / 09 / 08$ & 12.0 & $2.10( \pm 0.22)$ & $0.071( \pm 0.007)$ & 21 & 99 & 36.83 & 0.324 \\
\hline $10 / 09 / 08$ & 14.0 & $2.18( \pm 0.29)$ & $0.072( \pm 0.010)$ & 23 & 102 & 27.19 & 0.348 \\
\hline $22 / 09 / 08$ & 13.0 & $1.08( \pm 0.15)$ & $0.036( \pm 0.005)$ & 14 & 64 & 8.10 & 0.043 \\
\hline $17 / 09 / 07$ & 10.5 & $2.71( \pm 0.08)$ & $0.092( \pm 0.001)$ & 37 & 141 & 43.55 & 0.676 \\
\hline $23 / 07 / 05 a$ & 12.5 & $2.13( \pm 0.30)$ & $0.071( \pm 0.010)$ & 18 & 88 & 28.81 & 0.334 \\
\hline $23 / 07 / 05 b$ & 11.0 & $1.02( \pm 0.12)$ & $0.034( \pm 0.004)$ & 11 & 39 & 10.10 & 0.037 \\
\hline $13 / 08 / 04$ & 10.0 & $1.84( \pm 0.33)$ & $0.063( \pm 0.011)$ & 21 & 92 & 19.96 & 0.232 \\
\hline
\end{tabular}

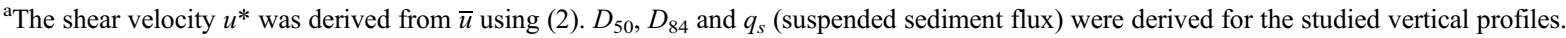


Table 2. Sediments Sampled on the Ganga at Harding Bridge With Sampling Date, Sample Type, Sampling Depth Above the River Bottom, Sediment Load, and Grain Size Parameters $D_{50}$, $D_{84}$, and $D_{90}$

\begin{tabular}{|c|c|c|c|c|c|c|}
\hline Sample & Type $^{\mathrm{a}}$ & $\begin{array}{l}\text { Height Above Bottom } \\
\qquad(\mathrm{m})\end{array}$ & $\begin{array}{c}\text { Load } \\
(\mathrm{g} / \mathrm{l})\end{array}$ & $\begin{array}{l}\mathrm{D} 50 \\
(\mu \mathrm{m})\end{array}$ & $\begin{array}{l}\mathrm{D} 84 \\
(\mu \mathrm{m})\end{array}$ & $\begin{array}{l}\mathrm{D} 90 \\
(\mu \mathrm{m})\end{array}$ \\
\hline \multicolumn{7}{|c|}{$08 / 07 / 10$} \\
\hline BR1026 & SL & 9.7 & 0.14 & 7.0 & 17.9 & 22.8 \\
\hline BR1025 & SL & 5 & 0.21 & 7.4 & 25.4 & 38.9 \\
\hline BR1024 & SL & 1 & 0.24 & 8.1 & 28.1 & 41.4 \\
\hline BR1028 & SL & 0.2 & 0.27 & 8.9 & 33.7 & 49.9 \\
\hline \multicolumn{7}{|c|}{$01 / 09 / 08$} \\
\hline BR8222 & SL & 11.9 & 0.92 & 11.1 & 39.9 & 53.8 \\
\hline BR8218 & SL & 10 & 1.39 & 18.8 & 86.8 & 124.8 \\
\hline BR8217 & SL & 8 & 1.59 & 17.1 & 70.7 & 91.5 \\
\hline BR8216 & SL & 5 & 1.59 & 24.8 & 126.4 & 167.1 \\
\hline BR8215 & SL & 0.1 & 3.30 & 109.0 & 213.9 & 246.0 \\
\hline BR8219A & tri SL & 1.1 & 1.51 & 38.6 & 170.6 & 205.3 \\
\hline BR8219B & tri SL & 0.6 & 1.78 & 33.4 & 145.0 & 175.5 \\
\hline BR8219C & tri SL & 0.1 & 1.36 & 50.6 & 185.9 & 218.5 \\
\hline BR8221 & BL & & & 259.4 & 353.8 & 386.8 \\
\hline \multicolumn{7}{|c|}{$10 / 09 / 08$} \\
\hline BR8253 & SL & 13.9 & 0.62 & 11.7 & 39.9 & 53.0 \\
\hline BR8250 & SL & 5 & 1.08 & 22.8 & 93.8 & 123.0 \\
\hline BR8251 & SL & 2 & 1.19 & 26.6 & 113.1 & 151.9 \\
\hline BR8255a & tri SL & 1.1 & 1.15 & 21.2 & 87.2 & 116.8 \\
\hline BR8255b & tri SL & 0.6 & 1.15 & 20.5 & 83.5 & 112.0 \\
\hline BR8255c & tri SL & 0.1 & 1.30 & 32.6 & 125.4 & 158.8 \\
\hline BR8256a & tri SL & 1.1 & 1.40 & 33.6 & 140.3 & 173.3 \\
\hline BR8256b & tri SL & 0.6 & 1.23 & 27.3 & 129.1 & 170.3 \\
\hline BR8256c & tri SL & 0.1 & 1.49 & 46.2 & 179.1 & 213.5 \\
\hline BR8252 & BL & & & 228.2 & 325.8 & 407.2 \\
\hline \multicolumn{7}{|c|}{$22 / 09 / 08$} \\
\hline BR8281 & SL & 12.9 & 0.37 & 10.6 & 32.2 & 43.7 \\
\hline BR8280 & SL & 8 & 0.61 & 13.5 & 55.2 & 76.1 \\
\hline BR8279 & SL & 3 & 0.60 & 14.5 & 67.3 & 101.1 \\
\hline BR8283 & BL & & & 269.0 & 361.7 & 398.7 \\
\hline \multicolumn{7}{|c|}{$17 / 08 / 07$} \\
\hline BR713 & SL & 0.5 & 3.08 & 91.8 & 172.0 & 195.9 \\
\hline BR714 & SL & 2.5 & 2.24 & 52.6 & 158.1 & 185.2 \\
\hline BR715 & SL & 7.5 & 1.44 & 24.3 & 111.8 & 144.2 \\
\hline BR716 & SL & 10.4 & 0.71 & 13.4 & 41.8 & 56.5 \\
\hline BR 718 A & tri SL & 1.1 & 2.37 & 53.8 & 160.5 & 185.5 \\
\hline BR 718 B & tri SL & 0.6 & 3.07 & 83.0 & 170.4 & 194.3 \\
\hline BR $718 \mathrm{C}$ & tri SL & 0.1 & 6.55 & 127.3 & 196.8 & 216.0 \\
\hline BR717 & BL & & & 184.5 & 265.6 & 300.9 \\
\hline \multicolumn{7}{|c|}{$23 / 07 / 05 a$} \\
\hline BR 515 & SL & 10.9 & 0.94 & 8.4 & 23.2 & 30.4 \\
\hline BR 514 & SL & 8.5 & 1.42 & 12.2 & 49.7 & 69.4 \\
\hline BR 513 & SL & 6 & 1.71 & 13.9 & 58.2 & 78.4 \\
\hline BR 512 & SL & 4 & 1.81 & 17.3 & 84.9 & 110.3 \\
\hline BR 511 & SL & 1 & 2.44 & 30.6 & 100.2 & 122.2 \\
\hline BR 516 & BL & & & 176.5 & 284.1 & 325.3 \\
\hline \multicolumn{7}{|c|}{$23 / 07 / 05 b$} \\
\hline BR 519 & SL & 9.9 & 0.66 & 7.6 & 19.2 & 24.8 \\
\hline BR 518 & SL & 5 & 1.53 & 12.9 & 52.6 & 71.7 \\
\hline BR 517 & SL & 0.2 & 1.81 & 15.8 & 69.2 & 87.2 \\
\hline \multicolumn{7}{|c|}{$13 / 07 / 04$} \\
\hline BR 415 & SL & 9.9 & 0.80 & 9.8 & 33.3 & 45.2 \\
\hline BR 414 & SL & 8 & 1.00 & 13.4 & 47.1 & 65.4 \\
\hline BR 413 & SL & 6 & 1.30 & 16.4 & 63.3 & 84.7 \\
\hline BR 412 & SL & 3.5 & 1.50 & 20.8 & 88.9 & 119.8 \\
\hline BR 411 & SL & 1 & 2.90 & 56.3 & 163.9 & 192.1 \\
\hline BR 418 & $\mathrm{BL}$ & & & 215.3 & 293.2 & 329.7 \\
\hline
\end{tabular}

Table 2. (continued)

\begin{tabular}{lcccccc}
\hline Sample & Type $^{\mathrm{a}}$ & $\begin{array}{c}\text { Height Above Bottom } \\
(\mathrm{m})\end{array}$ & $\begin{array}{c}\text { Load } \\
(\mathrm{g} / \mathrm{l})\end{array}$ & $\begin{array}{c}\mathrm{D} 50 \\
(\mu \mathrm{m})\end{array}$ & $\begin{array}{c}\text { D84 } \\
(\mu \mathrm{m})\end{array}$ & $\begin{array}{c}\text { D90 } \\
(\mu \mathrm{m})\end{array}$ \\
\hline & \multicolumn{7}{c}{$16 / 07 / 02$} \\
BR 212 & SL & 21 & & & & \\
BR 211 & SL & 18.5 & 0.57 & 9.3 & 28.1 & 38.4 \\
BR 209 & SL & 17 & 0.75 & 10.7 & 37.6 & 51.5 \\
BR 208 & SL & 12 & 0.74 & 10.8 & 37.0 & 51.6 \\
BR 210 & SL & 5 & 1.25 & 22.8 & 72.9 & 58.0 \\
BR 214 & BL & & & 129.9 & 212.6 & 248.4 \\
\end{tabular}

${ }^{\mathrm{a}} \mathrm{SL}$, suspended load; tri SL, bottom triple sampler; BL, bedload.

column is positively correlated to $D_{84}$. Other trace minerals such as Ce, Dy, Er, Gd, Ge, Ho, La, Lu, Nd, Ni, Pr, Sr, Ta, Th, Tm, U, W, Y and $\mathrm{Yb}$ are not affected by mineral sorting in the suspended load and have even concentrations over the entire range of $D_{84}$ values even if they may be strongly enriched in the dredged bed load samples. Finally a few elements: $\mathrm{In}, \mathrm{Sb}, \mathrm{Sm}$ and $\mathrm{Sn}$, do not show any relation with grain size and have very variable concentration through the water column. Elements strongly enriched in the bed load also show a large sample-to-sample variability, suggesting that these elements are associated to dense minerals and affected by placer effects (see Garzanti et al. [2010, 2011] for a mineralogical study of Ganga sediments).

[28] The relations between chemical composition and grain-size can be conceptually understood as the effect of the hydrodynamic conditions on sediment transport as particles are segregated based on their settling velocity. Turbulent settling predicts that the settling velocity increases with particle radius and density. The abundance of coarse particles, such as quartz or albite grains and, to a lesser extent, micas is diluting other minerals in the water column. This dilution is maximum close to the bottom where coarse-grained quartz concentration is maximum. This implies that bottom sediments are enriched in elements such as $\mathrm{Si}$ while surface sediments are enriched in $\mathrm{Al}, \mathrm{Fe}$ and other elements carried in small or platy minerals such as micas or clays.

\section{Sediment Composition Modeling}

[29] To determine the chemical composition and flux of the sediments we use the strong correlation that exists between the grain size and chemical composition of Ganga sediments. Deriving the grain size of transported sediments requires prediction of the average flux of sediments in every grain-size class, $Q_{s}^{i}$. For this, the velocity field $u(z, x, t)$ and the concentration of sediments in every grain size class $C^{i}(z, x, t)$ should be predicted and extrapolated spatially across the river channel $(d x, d z)$ and temporally across the hydrograph $(d t)$ over the studied period $\mathrm{T}$, following equation (2):

$$
Q_{s}^{i}=\frac{1}{T} \iiint C^{i}(z, x, t) \cdot u(z, x, t) \cdot d z \cdot d x \cdot d t
$$

The total average sediment flux $Q_{t}$ is simply derived by summing $Q_{s}^{i}$ of every grain size class:

$$
Q_{t}=\sum_{i} Q_{s}^{i}
$$



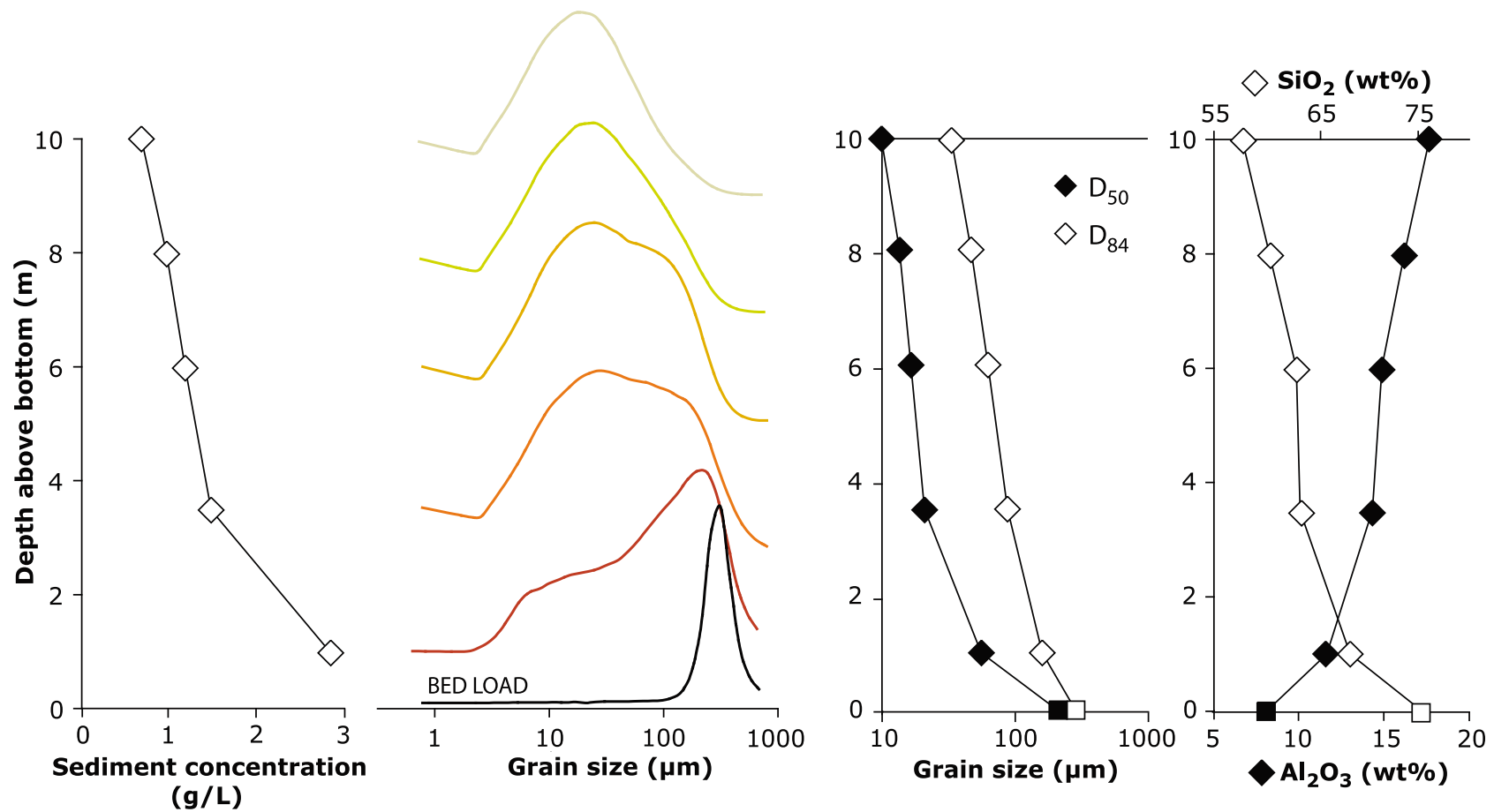

Figure 6. Vertical profile of suspended sediment concentration, grain size distribution, grain size parameters $D_{84}, D_{50}$ and chemical composition $\left(\mathrm{SiO}_{2}\right.$ and $\mathrm{Al}_{2} \mathrm{O}_{3}$ wt\%) of the Ganga sediments $(13 / 08 / 2004$ profile). Diamonds denote suspended sediments and squares, dredged sediment.

The average chemical composition $[X]$ and flux $Q_{X}$ for element $\mathrm{X}$ of the exported sediments is given by:

$$
Q_{X}=[X] \cdot Q_{t}=f\left(D_{84}\right) \cdot Q_{t}
$$

In the following we explore the possibility to use a fully predictive model as described by equation (3) and equation (4) to estimate the grain size composition of the Ganga sediments.

\subsection{Vertical Particle Concentration}

\subsubsection{Rouse Model}

[30] Sediment transport and concentration profiles in open channel have been the focus of several decennia of extensive work using both theoretical approaches and flume experiments [e.g., Vanoni, 1946; Coleman, 1970; Mazumder, 1994; Muste and Patel, 1997; Cellino and Graf, 1999; Graf and Cellino, 2002; Mazumder et al., 2005, Mazumder and Ghoshal, 2006]. The variation of suspended sediment concentration with depth in large alluvial rivers has also been recognized for a long time and at the first order the concentration profile of sediments in a water column can be described by the Rouse equation [Rouse, 1950]:

$$
C^{i}(z)=C_{0}^{i} \cdot\left(\frac{(H-z) / z}{\left(H-z_{0}\right) / z_{0}}\right)^{Z_{R}^{i}} ; Z_{R}^{i}=\frac{w_{s}^{i}}{\beta \cdot \kappa \cdot u_{Z, r}^{*}}
$$

with $C^{i}(z)$ being the concentration of the grain size class $i$ at a height $z$ above the bed, $C_{0}^{i}$ the reference concentration of sediments in the grain size class $i$ at the reference height $z_{0}$ above the bed. The Rouse number, $Z_{R}^{i}$, is defined as the ratio of the settling velocity, $w_{s}^{i}$ and the bottom shear velocity $u_{Z_{r}}^{*}$ with $\kappa$ being the von Karman constant (taken as 0.41 [Garcia,
2008]) and $\beta$ the ratio of sediment and water momentum diffusion coefficients, generally assumed to be 1 [e.g., Muste et al., 2005].

[31] For each grain size class, Ganga concentration profiles are well described by the Rouse equation (5) (Figure 8), which enables the prediction of the concentration over the full water column. For this study the reference height was taken as a fixed fraction of total water depth $H(a=0.001 \cdot H)$ while $C_{0}$ and $Z_{r}$ were adjusted to fit the concentration data. No general consensus exists in the literature about the reference height. The transition between bed load and suspended load covers a wide range of values from $3 \cdot D_{90}$ [Smith and McLean, 1977] to $0.01 \cdot H$ [van Rijn, 1984a]. Sediment concentration of samples collected near the bottom $(10 \mathrm{~cm} \sim$ $0.01 \cdot H$ ) did not exceed $6.5 \mathrm{~g} / 1$ and were thus not considered as being part of the proper bed load flux.

[32] For all profiles, the Rouse number increases with grain size implying that coarse particles are strongly segregated and concentrated near the bottom while fine particles are distributed homogeneously through the water column. Near bottom concentrations also increase with grain size even though for several profiles (01/09/2008, 17/08/2007 and $23 / 07 / 2005$ ) the maximum modeled concentration at the reference height is in the range of 150-250 $\mu \mathrm{m}$, which corresponds to the average mode of bed load sediments.

\subsection{2. $\beta$ Factor and Grain Size}

[33] Predicting the full sediment concentration profile from the Rouse equation (5) requires $\beta$ and the fall velocity $w_{s}$ to be known. The fall velocity law derived by Dietrich [1982] is used for $w_{s}$ and $\beta$ can then be computed as the ration $u_{Z r}^{*} / u^{*}$, where $u^{*}$ is the shear velocity derived from ADCP measurements and $u_{Z r}^{*}$ the shear velocity derived from fitting the Rouse profile to the available sediment samples. This shows 

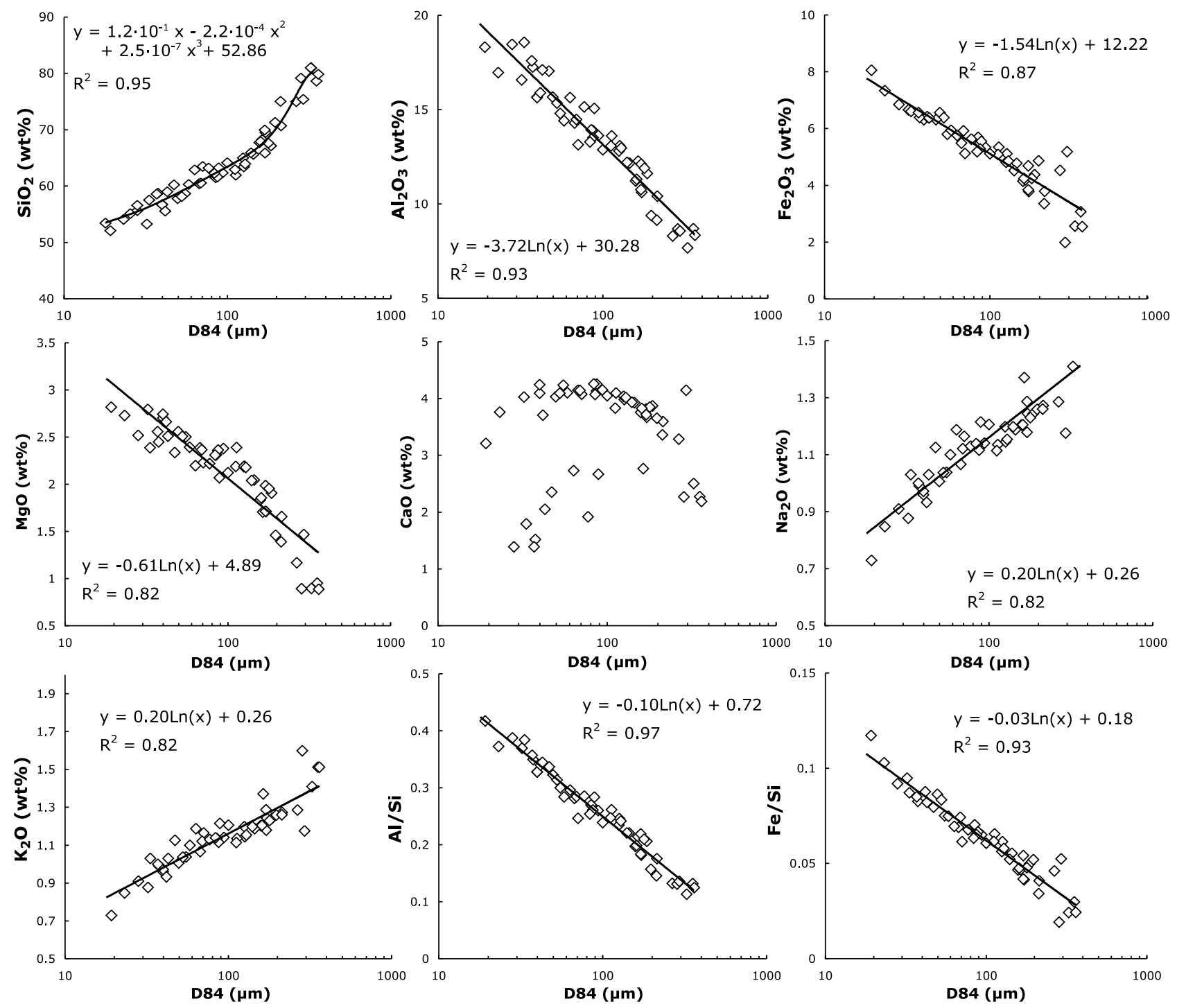

Figure 7. Relation between chemical major element composition of sediments and grain size parameter $D_{84}$. Concentration in major elements is primarily controlled by the grain size of the bulk sample. Regressions are improved by using normalized ratios such as $\mathrm{Al} / \mathrm{Si}$ or $\mathrm{Fe} / \mathrm{Si}$ (molar ratios) as these ratios exclude dilution by variable carbonate content.

that $\beta$ is not constant over all grain sizes and does not equal 1 (Figure 9). It has long been recognized that the ratio of sediment and water momentum diffusion coefficients depends on $w_{s} / u^{*}$, which directly influences the value of $\beta$ in river and channels [Nordin and Dempster, 1963; Coleman, 1970; Bennett et al., 1998; Graf and Cellino, 2002]. Deviations of $\beta$ from unity have been inferred from experimental data [e.g., van Rijn, 1984b] (also represented in Figure 9), field measurements in the Mississippi River [Jordan, 1965; Scott and Stephens, 1966] and in the Amazon River [Bouchez et al., 2010]. Several reasons have been invoked. First, $\beta$ is sensitive to the sediment settling velocity law used and the settling velocity may be overestimated in the case of flaky and fine grained sediments that are not well determined by diffraction grain size analyzers [McCave et al., 2006]. Second, Bouchez et al. [2011a] stressed the effect of particle aggregation on $\beta$ in the Amazon River. Aggregation is typical of fresh water environments [e.g., Walling and Moorehead, 1989; Droppo and Ongley, 1994] and acts on settling velocities through changes in apparent size and density of the transported sediments. Because aggregates are disintegrated after collection [Phillips and Walling, 1995], the computed $\mathrm{w}_{\mathrm{s}}$ and therefore $\beta$ could be biased.

[34] The use of $u^{*}$ measurements along with a single surface sediment sample would theoretically be sufficient to predict the whole vertical profile using the Rouse model [Bouchez et al., 2011a]. We do not obtain, however, a single relation for $\beta$ over the different sediment profiles, which might arise from our depth-sampling repositioning strategy or from the underlying assumptions that the Rouse equation is derived for an equilibrium profile where local erosion matches deposition, which might not always be the case in our profiles. Those systematic but temporally scattered deviations from unity prevent therefore to use, in this study, 


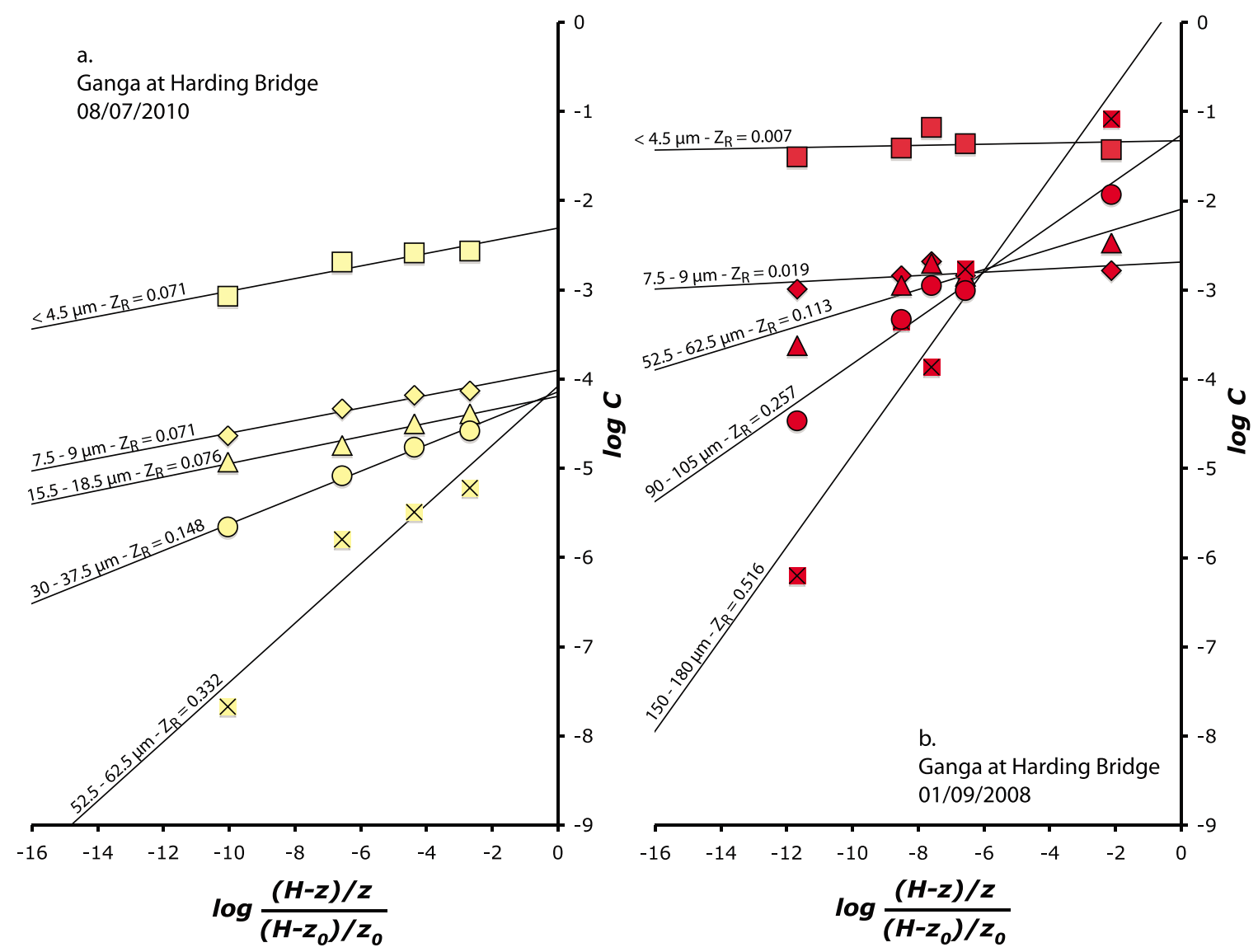

Figure 8. Variation in concentration with depth (Rouse coordinates) of different grain size classes of two sampled verticals from the Ganga at Harding Bridge ((a) 08/07/2010 and (b) 01/09/2010). As grain size increases, the gradient of sediment concentration increases (increasing $Z_{R}$ ).

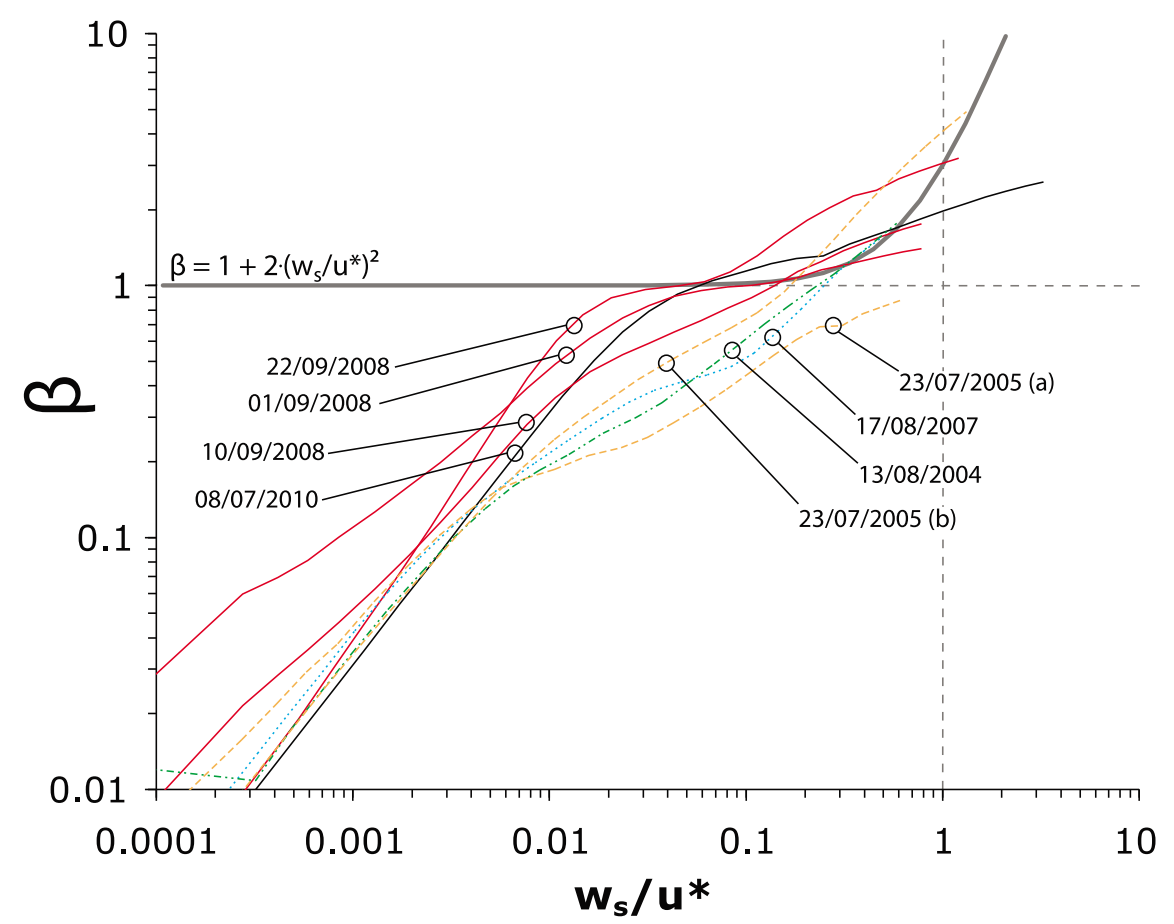

Figure 9. Evolution of $\beta$ as function of $w_{s} / u^{*}$ for the different profiles of the Ganga at Harding Bridge. The relation derived by van Rijn [1984b], $\beta=1+2 \cdot\left(w_{s} / u^{*}\right)^{2}$, is also plotted for comparison. 

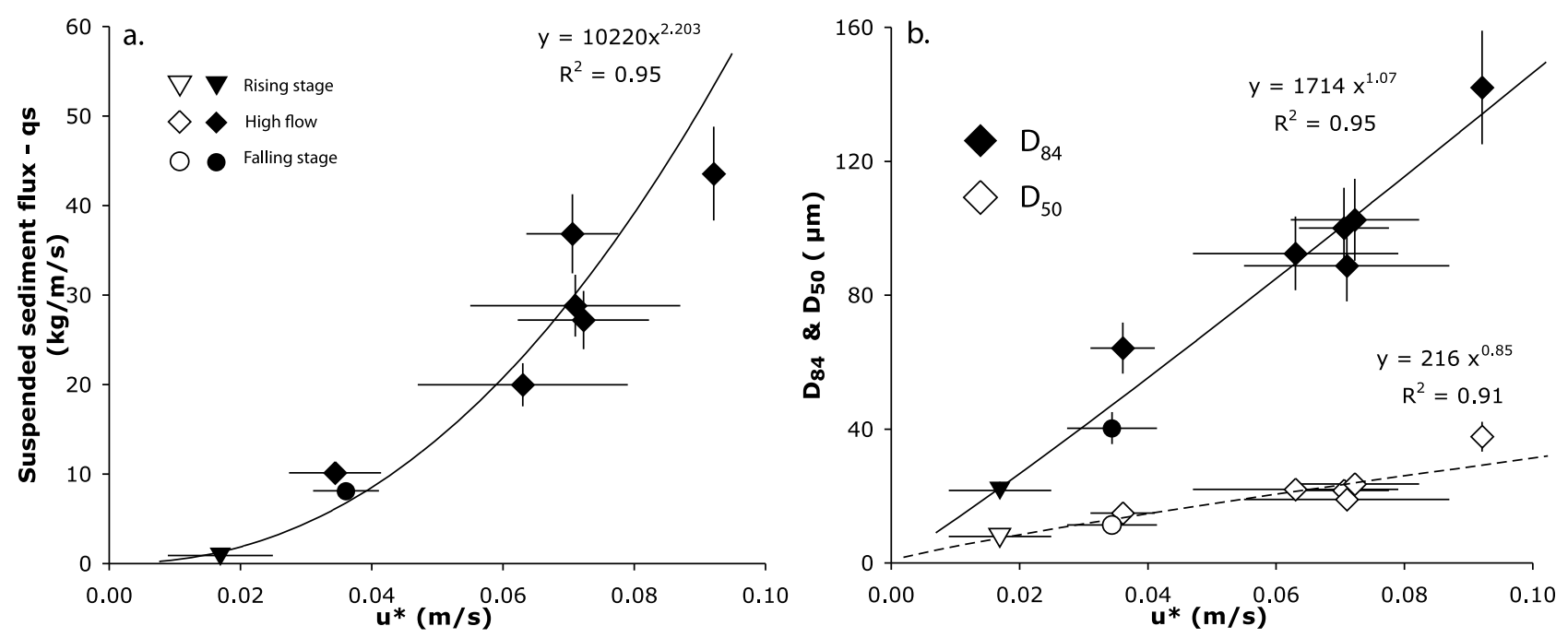

Figure 10. (a) Instantaneous suspended sediment flux and (b) $D_{84}-D_{50}$ of the transported sediments as a function of friction velocity $u^{*}$. Data points were obtained from extrapolation of concentration of the different grain size classes of the samples through the water column and integration over depth. Local hydrodynamic conditions are a first order control on sediment transport with higher fluxes of coarser sediments being transported with increasing $u^{*}$. Rising and falling stage samples are marked respectively by a triangle and circle and do not show any clear departure from the general trend.

the Rouse model as a purely predictive model to extrapolate the concentration based on measured or modeled shear velocities alone.

\subsection{Instantaneous Sediment Fluxes and Grain Size}

\subsubsection{Suspended Load}

[35] To circumvent the difficulties of predicting the Rouse profile in space and time, we consider in the following a more empirical approach, by analogy to classical sediment transport capacity expressions that are expressed as a function of $u^{*}$ or $\tau_{0}$. The instantaneous sediment flux per width unit $\left(q_{s}^{i}\right)$ for every grain size class $(i)$ through a vertical column can be computed from the water velocity profile and the sediment concentration obtained from fitting the Rouse profile equation (5) to the sampled column following equation (6):

$$
q_{s}^{i}=\int_{0.001 \cdot H}^{H} C^{i}(z) \cdot u(z) \cdot d z
$$

where $C^{i}(z)$ is the concentration of grain size $i$ at depth $z$, $u(z)$ the velocity at depth $z$ and $H$ the water height. The computed $D_{50}$ and $D_{84}$ of the sediments transported through the water column are reported in Table 1 along with the total sediment flux and the associated shear velocities of the profile. Uncertainties in the predicted $D_{84}\left(D_{50}\right)$ and flux for a vertical profile were estimated as the average residual of the modeled and measured $D_{84}\left(D_{50}\right)$ and flux of each sample, respectively 11 and $12 \%$.

[36] The deduced, grain size parameters and instantaneous total sediment fluxes are positively correlated to the local hydrodynamic conditions using a power law type of relation: $q_{s}=\alpha \cdot u^{* \gamma}(r>0.9)$ (Figure 10). This relation holds also for individual grain size classes, $q_{s}^{i}$ and friction velocity (Appendix A). High levels of hydraulic energy (high $u^{*}$ ) are consistent with high-suspended sediment transport stages of coarser material. Samples collected during rising and falling water level stage do not deviate significantly from the trend defined by high flow samples suggesting a limited hysteresis effect and we assume that a single $q_{s}^{i}=f\left(u^{*}\right)$ relation is sufficient to describe sediment transport in the Ganga. This relation is used to build a predictive model for the sediment flux of a vertical water column, in every grain size class equation (7) that requires only knowledge of the friction velocity $\left(u^{*}\right)$ and can be integrated over the river crosssection $(d x)$ and through the hydrograph $(d t)$.

$$
Q_{s}^{i}=\frac{1}{T} \iint q_{s}^{i}\left(u^{*}\right) \cdot d x \cdot d t
$$

\subsubsection{Bed Load Fluxes}

[37] The precise determination of the amount of sediment mobilized as bed load has proven to be difficult and several studies have provided parameterizations of bed load fluxes [e.g., Garcia, 2008]. In this study, bed load fluxes $\left(q_{b}\right)$ were estimated using a simplified formula for bed load transport, proposed by van Rijn [1984a, 1993] and recalibrated on natural sand-bed river bed load transport data sets [van Rijn, 2007]:

$$
q_{b}=\varepsilon \cdot \rho_{s} \cdot \bar{u} \cdot H \cdot\left(\frac{D_{50}}{H}\right)^{1.2} \cdot\left(M_{e}\right)^{\eta} ; M_{e}=\frac{\bar{u}-\bar{u}_{c r}}{\sqrt{R \cdot g \cdot D_{50}}}
$$

with $\bar{u}$ the depth average water velocity, $\bar{u}_{c r}$ the depth averaged critical velocity deduced from the critical shear stress for initiation of motion using the Shields diagram and equation (1), $H$ the water column height, $R=\left(\rho_{s}-\rho\right) / \rho$ the submerged specific gravity of the sediment and the coefficients $\varepsilon=0.015$ and $\eta=1.5$.

[38] Instantaneous bed load fluxes calculated using this formulation range from $0.002 \mathrm{~kg} / \mathrm{m} / \mathrm{s}$ for the $08 / 07 / 2010$ profile to $0.680 \mathrm{~kg} / \mathrm{m} / \mathrm{s}$ for the most energetic conditions of 

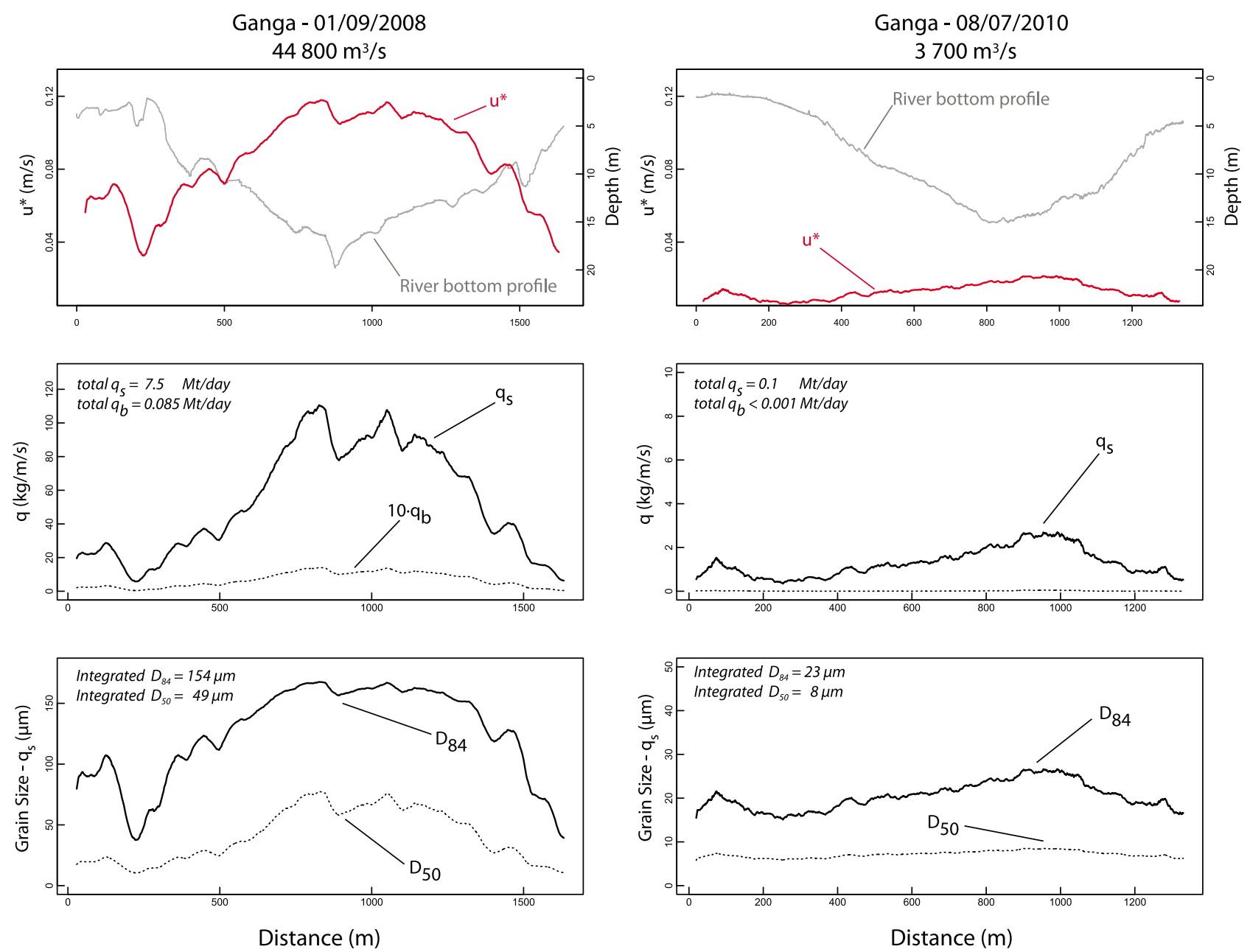

Figure 11. Spatial integration of the suspended sediment flux $\left(q_{s}\right)$, bed load flux $\left(q_{b}\right)$ and $D_{50}, D_{84}$ grain size of two transects of the Ganga at Harding Bridge (01/09/2008 and 08/07/2010). The depth average velocity is computed from the ADCP velocity yielding the local $u^{*}$ value. Local $q_{s}, q_{b}$ and $D_{50}, D_{84}$ are deduced from the empirically calibrated relations (see text) and integrated over the whole river section to estimate the total instantaneous flux and grain size of the river.

17/08/2007. Comparison with the integrated suspended load fluxes shows that $q_{b} / q_{s}<0.016$ for all vertical profiles of this study. The ratio $q_{b} / q_{s}$ increases with $u^{*}$, for a constant depth, but the instantaneous bed load flux as formulated above represents less than $2 \%$ of the suspended load for $u^{*}<$ $0.15 \mathrm{~m} / \mathrm{s}(\bar{u}=4.3 \mathrm{~m} / \mathrm{s}$ for $H=10 \mathrm{~m})$ which represents a probable upper limit of the flow of the Ganga at Harding Bridge. The ratio $q_{b} / q_{s}$ is dependant on the chosen transition height between bed load flux and suspended-load flux, which is not universally agreed on, as discussed earlier. Nevertheless, choosing a reference height of $0.01 \cdot H$ instead of the $0.001 \cdot H$ for the suspended load integration and keeping $q_{b}$ constant, only slightly increases $q_{b} / q_{s}$ from 0.0155 to 0.0165 for the $17 / 08 / 2007$ vertical profile.

[39] This bed load to suspended load ratio is lower than that found in some other sandbed rivers where it may reach well over 30\% [e.g., Abdel-Fattah et al., 2004; Turowski et al., 2010]. We emphasize that bed load fluxes found here are in the same order of magnitude as in other studies [e.g., Gaweesh and van Rijn, 1994; Abdel-Fattah et al., 2004] and the low $q_{b} / q_{s}$ are thus essentially caused for the Ganga by high suspended sediment concentrations and integrated volumes over large water depth. This observation agrees with a general decreasing trend in $q_{b} / q_{s}$ with increasing suspended load concentrations found in the data set compiled by Turowski et al. [2010]. However, our ratio cannot easily be extrapolated to the entire Ganga reach as the Harding Bridge section is a single-thread, relatively narrow channel compared to up and downstream sections. Flow acceleration may increase the bed shear velocity transferring a significant amount of sediments from bed load to suspended load transport.

\subsection{Integration of Sediment Flux and Grain Size 4.3.1. Lateral Extrapolation of Sediment Fluxes} and Grain-Size

[40] Using the ADCP channel transects we derived the local $u^{*}$ across the channel and computed the sediment flux and grain size according to equation (7) (Figure 11). Bed load fluxes are estimated using equation (8). The sediment flux integrated over the whole river section was computed for the samplings of 2004, 2007, 2008 and 2010 when full channel 
Table 3. ADCP Measured Discharges and Gauged Water Level of the Ganga at Harding Bridge

\begin{tabular}{ccccccc}
\hline Sampling Date & $\begin{array}{c}\text { Measured Q } \\
\left(\mathrm{m}^{3} / \mathrm{s}\right)\end{array}$ & $\begin{array}{c}\text { Water Level } \\
(\mathrm{m})\end{array}$ & $\begin{array}{c}q_{s} \\
(\mathrm{Mt} / \mathrm{d})\end{array}$ & $\begin{array}{c}D_{50} q_{s} \\
(\mu \mathrm{m})\end{array}$ & $\begin{array}{c}D_{84} q_{s} \\
(\mu \mathrm{m})\end{array}$ & $\begin{array}{c}q_{b} \\
(\mathrm{Mt} / \mathrm{d})\end{array}$ \\
\hline $13 / 08 / 10$ & 3700 & 9.5 & $0.14( \pm 0.02)$ & $7.6( \pm 1.4)$ & $22.5( \pm 2.9)$ & $<0.001$ \\
$01 / 09 / 08$ & 44800 & 13.8 & $7.51( \pm 0.41)$ & $49.8( \pm 6.7)$ & $153.6( \pm 9.4)$ & 0.085 \\
$10 / 09 / 08$ & 32000 & 13.2 & $4.46( \pm 0.18)$ & $29.6( \pm 2.7)$ & $126.9( \pm 7.1)$ & 0.051 \\
$22 / 09 / 08$ & 18000 & 11.4 & $0.99( \pm 0.05)$ & $12.2( \pm 1.0)$ & $49.4( \pm 3.5)$ & 0.007 \\
$17 / 08 / 07$ & 41500 & 13.6 & $6.20( \pm 0.32)$ & $45.8( \pm 5.8)$ & $150.2( \pm 9.6)$ & 0.071 \\
$13 / 08 / 04$ & 30400 & 12.2 & $2.53( \pm 0.09)$ & $16.1( \pm 1.0)$ & $76.7( \pm 4.7)$ \\
\hline
\end{tabular}

${ }^{\text {a }}$ The values $q_{s}$ and $q_{b}$ are the daily fluxes of suspended and bed load sediments computed from spatial extrapolation of sampled vertical profiles. Modeled average $D_{50}$ and $D_{84}$ grain size parameters of the suspended load of the Ganga is also reported.

ADCP transects were performed (Table 3). Total suspended fluxes reach over $7 \mathrm{Mt} /$ day of coarse sediments during high flow but drop to less than $0.2 \mathrm{Mt} /$ day of fine grained sediments when the water level drops by ca. $4 \mathrm{~m}$. Integrated bed load fluxes represent less than $100 \mathrm{t} /$ day for the 2010 section and reach $150000 \mathrm{t} /$ day during high flow as calculated for the $01 / 09 / 2008$ section. Uncertainty in the modeled fluxes and grain size distributions was propagated from the uncertainty in the fitted power law between $u^{*}$ and $q_{s}^{i}$ using a Monte Carlo approach.

\subsubsection{Annual Integration of the Sediment Flux and Grain Size}

[41] Variations in water level and discharge through the annual hydrological cycle of the Ganga govern sediment transport and have to be accounted for to compute average sediment flux and grain size over several years. In this model we use the measured hydrograph of the Ganga at Harding Bridge to predict first order variations in shear velocity in the river section and derive sediment fluxes and grain sizes.

[42] For a steady, turbulent, uniform, and open channel flow, the basal shear stress $\left(\tau_{0}\right)$ is a function of water height $(\mathrm{H})$ and the water energy slope ( $\mathrm{S}$ - generally approximated by the water surface slope) following $\tau_{0}=\rho g H S$. In many simplified settings, it is assumed that $\mathrm{S}$ is constant and equal to the regional slope. However, partial embankment and constriction upstream of the sampling site may affect the water surface slope of the Ganga at Harding Bridge.

[43] We estimate the local apparent energy slope, S, from the ADCP measurements using the local water depth $H$ and the calculated $u^{*}$ of a vertical water column. An average energy slope of the channel was then calculated by averaging the local values of $S$ over the central part of the channel (the lateral 100 to $200 \mathrm{~m}$ parts of the channel were not used). The average energy slope for the Ganga ranged from $2.4 \cdot 10^{-6}\left( \pm 1.5 \cdot 10^{-6}\right)$ the $08 / 07 / 2010$ to $73 \cdot 10^{-6}\left( \pm 17 \cdot 10^{-6}\right)$ between the lowest and highest discharge sections measured (Figure 12). $\mathrm{S}$ is positively correlated $\left(R^{2}=0.99\right)$ to the water level measured at the Harding Bridge gauging station and can be predicted at first order using a power law relation: $S=$ $2.19 \cdot 10^{-15} \cdot H^{9.24}$. The above relation is qualitatively consistent with direct measurements showing that the local slope is dependent on water discharge from $4 \cdot 10^{-5}$ during flood season to almost zero during lean season [Delft Hydraulics and Danish Hydraulics Institute, 1996] and with the average distal Ganga plain surface slope of $4 \cdot 10^{-5}$ [Singh et al., 2007].

[44] Using the available river section bottom profiles it is then possible, using the empirical relation for the water surface slope to predict variations in $u^{*}$ with changing water level. These values of $u^{*}$ can then be used to extrapolate fluxes and grain size spatially for each water level of the hydrological cycle. Water level measured at Harding Bridge from 1980 to 2005 (station \#90, FFWC and WARPO) was used to produce an average hydrograph of the Ganga (Table S4).

[45] The model was run using the four available river section profiles of 2008 and 2010 as reference profiles and averaged (Figure 13). High sediment transport rates of up to 5-6 Mt/day occur during peak flow whereas fluxes are almost negligible during non-monsoon. High transport rates are concomitant with coarse grain transport and $D_{50}$, $D_{84}$ reaching $35 \mu \mathrm{m}$ and $140 \mu \mathrm{m}$ respectively. The 24 year averaged modeled suspended sediment flux of the Ganga is $390( \pm 30) \mathrm{Mt} / \mathrm{yr}$, which is in reasonable agreement with previous studies (Table 4). The modeled average $D_{50}$ and $D_{84}$ are respectively of $27( \pm 4)$ and $123( \pm 9) \mu \mathrm{m}$. Bed load fluxes, as formulated in the model, appear limited with $4 \mathrm{Mt} / \mathrm{yr}$ which is ca. $1 \%$ of the total sediment flux. As for the lateral integration, model uncertainties were estimated from Monte Carlo realizations.

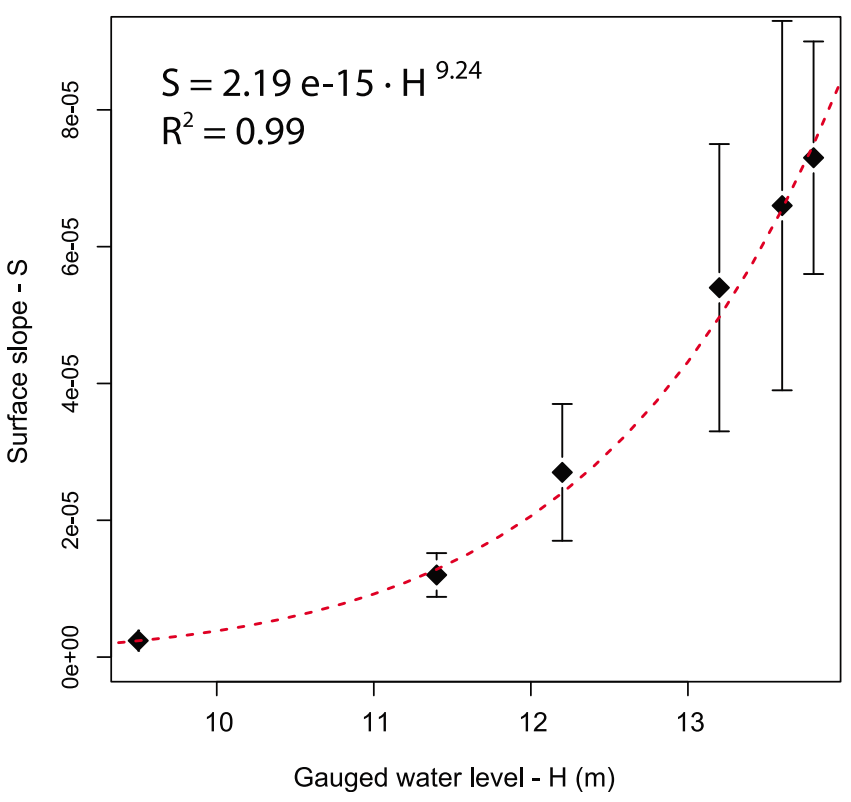

Figure 12. Evolution of the local surface slope of the Ganga at Harding Bridge as a function of the gauged water high. The local slope is derived from the interpretation of ADCP measurements. 

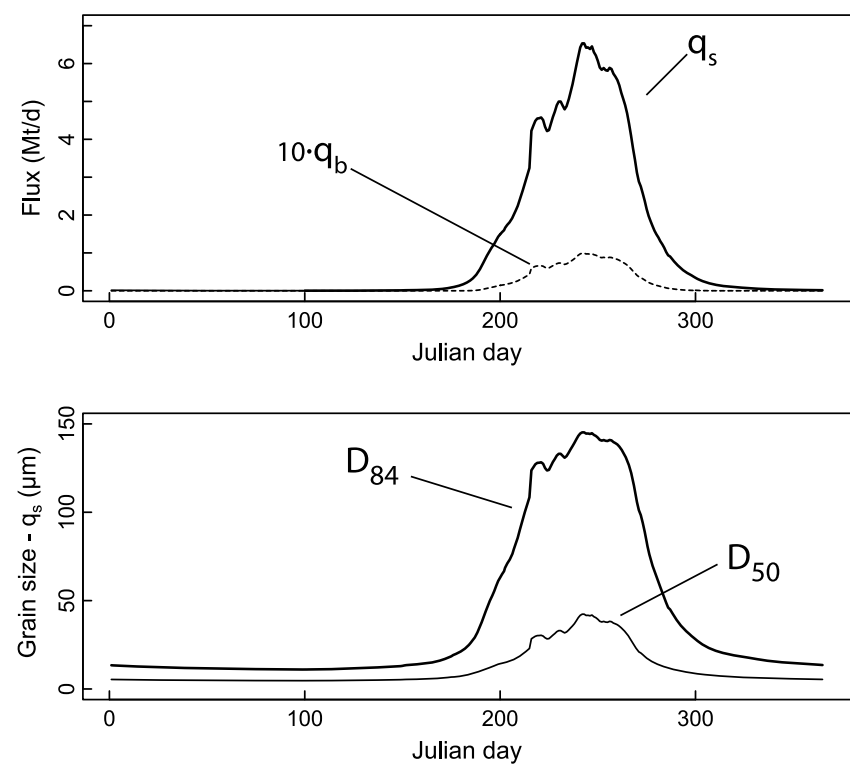

Figure 13. Modeled daily suspended sediment flux $\left(q_{s}\right)$, bed load flux $\left(q_{b}\right)$ and $D_{50}, D_{84}$ of transported sediments using a 24 year average hydrograph of the Ganga at Harding Bridge. The different curves were obtained from different river profiles (see text for details).

\subsection{Grain Size-Chemical Inversion}

[46] The integrated chemical composition of the Ganga is estimated from the modeled $D_{84}$ and the grain size - chemical compositions relations including bed load contribution (normalized to the Upper Continental Crust composition of Taylor and McLennan [1985, 1995] in Figure 14). For elements that do not show clear relationship with grain size (marked with an asterisk in Figure 14), the chemical composition reported here is derived from the simple average of all available samples. Detailed results for all elements are reported in Table 5.

[47] The integrated composition of Ganga sediments modeled in this work: $\mathrm{SiO}_{2}=66.91 \mathrm{wt} \%( \pm 1.03), \mathrm{Al}_{2} \mathrm{O}_{3}=$ $12.33 \mathrm{wt} \%( \pm 0.41), \mathrm{Fe}_{2} \mathrm{O}_{3}=4.75 \mathrm{wt} \%( \pm 0.20)$ is characterized by relatively high Si concentrations. Using this integrated composition, we estimate that the Ganga delivers annually $4.4 \cdot 10^{12}, 9.6 \cdot 10^{11}$ and $2.4 \cdot 10^{11} \mathrm{~mol}$ of particulate $\mathrm{Si}$, $\mathrm{Al}$ and $\mathrm{Fe}$ further downstream. Compared to the composition of surface suspended sediments, the integrated Ganga sediments are enriched in Si by $20 \%$ and depleted in $\mathrm{Al}, \mathrm{Fe}$ by $27 \%$ and $30 \%$ respectively. Carbonates represent only 2 to $4 \% \mathrm{wt}$ in our samples and cannot explain the depletion observed for $\mathrm{Al}$ and $\mathrm{Fe}$. For other elements the composition of the integrated Ganga and surface sediments is also significantly different by up to $120 \%$ for $\mathrm{Cd}$. This highlights that sorting effects have to be taken into account to derive reliable river sediment compositions and that a strong bias is introduced by analyzing surface samples only.

\section{Implication for Himalayan Geochemical Budget of Erosion}

[48] The flux of sediment calculated at Harding Bridge represents the major part of the modern Himalayan erosion flux but the Gangetic plain is the geomorphic evidence that part of the sedimentary flux is stored upstream of Bangladesh. Because sediments deposited in the floodplain are enriched in quartz relative to suspended sediments, geochemical mass balance allows this flux, hence the total flux of erosion in the Himalaya, to be constrained. This approach was followed by Galy and France-Lanord [2001] using suspended sediment compositions essentially derived from sediments sampled at the surface, hence much more aluminous than modeled in this study. Here, we revisit this budget with a Ganga sediment composition that is better constrained.

\subsection{Floodplain Sequestration}

[49] Figure 15 shows the chemical composition of the sediment flux at Harding Bridge compared with that of surface suspended load, UCC, the estimated Himalayan crust [Galy and France-Lanord, 2001], suspended and bed sediments of the Ganga, and Siwaliks for immobile elemental ratios $\mathrm{Al} / \mathrm{Si}$ and $\mathrm{Fe} / \mathrm{Si}$. The integrated sediment composition of the Ganga is only slightly differentiated compared to the average composition of the Himalayan crust. The Himalayan crust composition of Galy and France-Lanord [2001], is also very close to the average composition of suspended sediments sampled at the Himalayan outflow of Ganga, Karnali, and Narayani Rivers (Table S6). These dept samplings have been realized during peak flow at the center of the channel and very high turbulence prevents major differentiation in the water column, therefore the weighted average composition, unlike the Ganga in Bangladesh, likely approximates the average composition of the material exported from the Himalaya.

[50] The composition of the sediments stored in the floodplain is approximated by (1) the average composition of Siwaliks sediments from two sections from Nepal (Table S7)

Table 4. Compilation of Yearly Sediment Fluxes of the Ganga at Harding Bridge With Integration Period of Study When Available

\begin{tabular}{|c|c|c|c|c|}
\hline Study & $\begin{array}{c}\text { Mean Flux } \\
(\mathrm{Mt} / \mathrm{yr})\end{array}$ & $\begin{array}{l}\text { Maximum Flux } \\
(\mathrm{Mt} / \mathrm{yr})\end{array}$ & $\begin{array}{l}\text { Minimum Flux } \\
(\mathrm{Mt} / \mathrm{yr})\end{array}$ & Period \\
\hline Coleman $[1970]$ & 480 & 740 & 260 & $1958-1962$ \\
\hline Holeman [1968] & 1600 & & & \\
\hline Bangladesh Water Development Board [1972] & 448 & 482 & 430 & $1967-1969$ \\
\hline Master Plan Organization [1987] & 210 & & & \\
\hline French Engineering Consortium [1989] & 340 & & & \\
\hline China-Bangladesh Joint Expert Team [1991] & 200 & & & $1965-1988$ \\
\hline Hossain [1992] & 480 & & & $1962-1992$ \\
\hline Delft Hydraulics and Danish Hydraulics Institute [1996] & 548 & & & $1966-1970$ \\
\hline This study & 390 & 420 & 360 & $2004-2010$ \\
\hline
\end{tabular}



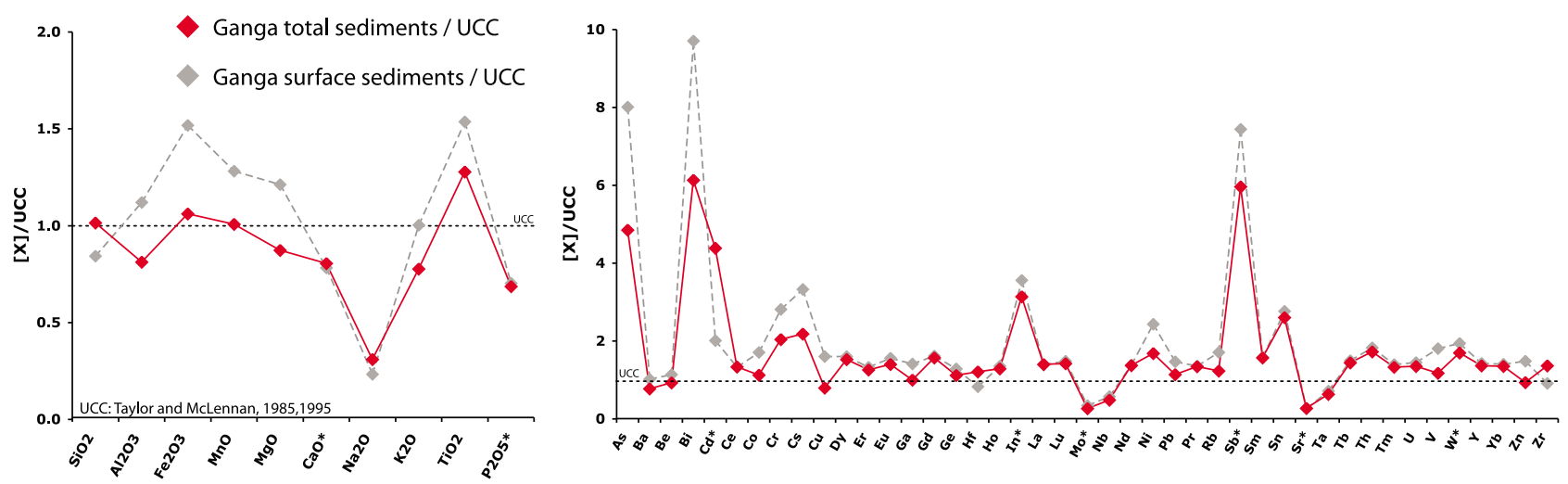

Figure 14. Chemical composition of integrated Ganga sediments modeled in this study (red) and Ganga surface sediments only (gray), normalized to the Upper Continental Crust (UCC) as defined by Taylor and McLennan [1985, 1995]. The integrated chemical composition was derived from the average $D_{84}$ of the Ganga sediments using the chemical composition - $D_{84}$ relationships observed (e.g., Figure 7) or the average of all available sediments when no correlation with $D_{84}$ is found (elements marked with an asterisk). Ganga surface sediments normalized to UCC are plotted in gray diamonds with dashed line for comparison with integrated Ganga sediments.

and, (2) the average composition of bed sediments, either dredged at the bottom of river channels during the monsoon or sampled in the river bed during dry season all over the Ganga floodplain (Table S8). Floodplain bed loads and Siwaliks sediments have comparable $\mathrm{Al} / \mathrm{Si}$ and $\mathrm{Fe} / \mathrm{Si}$ ratios even though absolute $\mathrm{Si}, \mathrm{Al}$ and $\mathrm{Fe}$ concentrations of the later are lower due to high carbonate content in Siwaliks rocks. Floodplain sediments may also store significant amounts of fine-grained material with higher $\mathrm{Al} / \mathrm{Si}$ ratios [Tripathi et al., 2007], which might lead to slight underestimation of the sequestered flux.

[51] Using the average chemical compositions of the different end-members of the Ganga system, we attempt to estimate the flux of sediments stored in the floodplain. This approach relies on the hypothesis that, at steady state, for any element the flux produced by Himalayan erosion must balance the sum of the corresponding elementary fluxes: sediments and solutes exported out of the basin plus sediments stored in the floodplain [Gaillardet et al., 1997; Galy and France-Lanord, 2001]. We derive the relative fluxes by solving a chemical mass balance for element $\mathrm{X}(\mathrm{Si}, \mathrm{Al}$, and $\mathrm{Fe}$ ) using compositions of the Himalayan bedrock (Him), the dissolved fluxes (Diss), the integrated transported sediments (ITS), and the floodplain sediments (FloodP).

$$
\Phi_{\text {Him }} \cdot[\mathrm{X}]_{\text {Him }}=\Phi_{\text {ITS }} \cdot[\mathrm{X}]_{\text {ITS }}+\Phi_{\text {Diss }} \cdot[\mathrm{X}]_{\text {Diss }}+\Phi_{\text {FloodP }} \cdot[\mathrm{X}]_{\text {FloodP }}
$$

We calculate $\Phi_{\text {FloodP }}$ using equation (9) for $\mathrm{Si}, \mathrm{Al}$ and Fe. Dissolved Si fluxes are taken from Galy and FranceLanord [1999] while dissolved $\mathrm{Al}$ and $\mathrm{Fe}$ fluxes are neglected in equation (9). The computed sequestration flux is $43( \pm 97) \mathrm{Mt} / \mathrm{yr}$, corresponding to a mean sequestration flux of ca. $10 \%$ of the total Himalayan eroded flux. This flux is quite limited, as expected given the chemical propinquity of the Ganga integrated sediments at Harding Bridge and Himalayan source compositions.
[52] Over the floodplain area (ca. $350000 \mathrm{~km}^{2}$ ), the calculated sequestration flux implies sedimentation rates of $0.08( \pm 0.19) \mathrm{mm} / \mathrm{yr}$ (for an average upper soil density in Bangladesh of $1500 \mathrm{~kg} / \mathrm{m}^{3}$ [FAO, 1971]). The large uncertainty does not exclude net erosion in the modern floodplain even if this is unlikely at the scale of the entire Ganga floodplain [Sinha et al., 2005]. Inferred sequestration fluxes are of the same order as local measured Holocene subsidence rates that span from 0.05 up to $1.5 \mathrm{~mm} / \mathrm{yr}$ [Joshi and Bhartiya, 1991; Sinha, 1996; Chandra et al., 2007]. From sediment volume reconstructions, Métivier et al. [1999] show that an amount equivalent to about $6 \%$ of the flux delivered to the Bay of Bengal is stored in the Ganga basin over the last $2 \mathrm{Ma}$.

\subsection{Erosion Rate of the Himalayan Sub-Basin}

[53] Assessing the actual Himalayan erosion rate requires summing the different fluxes involved. The net chemical erosion flux occurring as dissolved load, in the Ganga basin is limited to ca. $48 \mathrm{Mt} / \mathrm{yr}$ [Galy and France-Lanord, 1999]. Furthermore, non-Himalayan tributaries draining the Southern part of the Ganga basin were not accounted for. According to $\mathrm{Sr}, \mathrm{Nd}$ and $\mathrm{Os}$ isotopic signatures, the sediment flux associated to these rivers does not exceed $5 \%$ of the whole Ganga sediment flux [Singh et al., 2008; Paul, 2008]. But, part of the total Ganga flux is diverted into the Hooghly before Harding Bridge. According to Mukhopadhyay et al. [2006], the water discharge of the Hooghly represents less than $10 \%$ of the discharge at Harding Bridge. We therefore speculate that the sediment flux delivered by the nonHimalayan tributaries counterbalances the flux of sediments diverted into the Hooghly and that theses fluxes do not alter significantly our estimate of Himalayan erosion.

[54] Summing the physical and dissolved fluxes results in a total mass flux exported by the Himalaya of $485( \pm 112) \mathrm{Mt} / \mathrm{yr}$. Rescaled to the Himalayan area of the Ganga basin (ca. $210000 \mathrm{~km}^{2}$ ) this translates into an average erosion rate of the bedrock of $0.9( \pm 0.3) \mathrm{mm} / \mathrm{yr}$ (assuming a density of $2700 \mathrm{~kg} / \mathrm{m}^{3}$ ). These estimates are on the lower end of typical 
Table 5. Ganga Sediment Chemical Composition ${ }^{\mathrm{a}}$

\begin{tabular}{|c|c|c|c|c|}
\hline Element & $\begin{array}{l}\text { Integrated Sediment } \\
(\mathrm{BL}+\mathrm{SL})\end{array}$ & Bed Load & Surface Sediments & Integrated Sediment/UCC \\
\hline & $\mathrm{wt} \%$ & $w t \%$ & $w t \%$ & \\
\hline $\mathrm{SiO}_{2}$ & 65.29 & 76.77 & 55.39 & 0.99 \\
\hline $\mathrm{Al}_{2} \mathrm{O}_{3}$ & 12.35 & 8.70 & 17.01 & 0.81 \\
\hline $\mathrm{Fe}_{2} \mathrm{O}_{3}$ & 4.77 & 3.38 & 6.82 & 1.06 \\
\hline $\mathrm{MnO}$ & 0.07 & 0.08 & 0.09 & 1.01 \\
\hline $\mathrm{MgO}$ & 1.93 & 1.17 & 2.67 & 0.87 \\
\hline $\mathrm{CaO} *$ & 3.37 & 3.06 & 3.28 & 0.80 \\
\hline $\mathrm{Na}_{2} \mathrm{O}$ & 1.20 & 1.40 & 0.91 & 0.31 \\
\hline $\mathrm{K}_{2} \mathrm{O}$ & 2.64 & 1.90 & 3.40 & 0.78 \\
\hline $\mathrm{TiO}_{2}$ & 0.64 & 0.59 & 0.77 & 1.28 \\
\hline $\mathrm{P}_{2} \mathrm{O}_{5} *$ & 0.14 & 0.14 & 0.14 & 0.69 \\
\hline \multirow[t]{2}{*}{ LOI } & 5.83 & 2.61 & 8.96 & \\
\hline & mol:mol & mol:mol & mol:mol & mol:mol \\
\hline $\mathrm{Al} / \mathrm{Si}$ & 0.232 & 0.136 & 0.375 & 0.842 \\
\hline \multirow[t]{2}{*}{$\mathrm{Fe} / \mathrm{Si}$} & 0.056 & 0.034 & 0.095 & 1.082 \\
\hline & ppm & ppm & ppm & ppm \\
\hline As & 7.3 & 3.0 & 12.0 & 4.9 \\
\hline $\mathrm{Ba}$ & 427.5 & 296.4 & 561.5 & 0.8 \\
\hline $\mathrm{Be}$ & 2.7 & 2.4 & 3.4 & 0.9 \\
\hline $\mathrm{Bi}$ & 0.8 & 0.4 & 1.2 & 6.4 \\
\hline $\mathrm{Cd} *$ & 0.4 & 0.4 & 0.2 & 4.4 \\
\hline $\mathrm{Ce}$ & 85.2 & 155.8 & 85.0 & 1.3 \\
\hline Co & 11.3 & 6.1 & 17.1 & 1.1 \\
\hline $\mathrm{Cr}$ & 71.6 & 44.3 & 98.5 & 2.0 \\
\hline Cs & 8.1 & 4.2 & 12.3 & 2.2 \\
\hline $\mathrm{Cu}$ & 20.3 & 3.7 & 40.2 & 0.8 \\
\hline Dy & 5.3 & 8.7 & 5.6 & 1.5 \\
\hline $\mathrm{Er}$ & 2.9 & 4.8 & 3.1 & 1.3 \\
\hline $\mathrm{Eu}$ & 1.2 & 1.5 & 1.4 & 1.4 \\
\hline $\mathrm{Ga}$ & 17.0 & 11.3 & 24.1 & 1.0 \\
\hline $\mathrm{Gd}$ & 5.9 & 10.0 & 6.2 & 1.6 \\
\hline $\mathrm{Ge}$ & 1.8 & 1.8 & 2.1 & 1.1 \\
\hline $\mathrm{Hf}$ & 7.0 & 15.6 & 4.8 & 1.2 \\
\hline Ho & 1.0 & 1.7 & 1.1 & 1.3 \\
\hline In * & 0.2 & 0.1 & 0.2 & 3.1 \\
\hline $\mathrm{La}$ & 42.0 & 77.3 & 41.9 & 1.4 \\
\hline $\mathrm{Lu}$ & 0.5 & 0.8 & 0.5 & 1.4 \\
\hline Mo * & 0.4 & 0.0 & 0.5 & 0.3 \\
\hline $\mathrm{Nb}$ & 12.1 & 11.7 & 14.4 & 0.5 \\
\hline $\mathrm{Nd}$ & 35.7 & 63.7 & 36.0 & 1.4 \\
\hline $\mathrm{Ni}$ & 37.8 & 15.6 & 48.7 & 1.9 \\
\hline $\mathrm{Pb}$ & 22.8 & 17.6 & 29.5 & 1.1 \\
\hline $\operatorname{Pr}$ & 9.6 & 17.4 & 9.7 & 1.4 \\
\hline $\mathrm{Rb}$ & 138.7 & 87.6 & 191.6 & 1.2 \\
\hline $\mathrm{Sb} *$ & 1.2 & 0.8 & 1.5 & 5.9 \\
\hline $\mathrm{Sm}$ & 7.0 & 12.2 & 7.1 & 1.6 \\
\hline $\mathrm{Sn}$ & 6.5 & 10.4 & 6.9 & 2.6 \\
\hline $\mathrm{Sr} *$ & 97.3 & 94.8 & 92.5 & 0.3 \\
\hline $\mathrm{Ta}$ & 1.4 & 1.7 & 1.6 & 0.6 \\
\hline $\mathrm{Tb}$ & 0.9 & 1.5 & 1.0 & 1.4 \\
\hline Th & 18.4 & 34.7 & 19.6 & 1.7 \\
\hline $\mathrm{Tm}$ & 0.4 & 0.7 & 0.5 & 1.3 \\
\hline $\mathrm{U}$ & 3.8 & 6.3 & 4.1 & 1.4 \\
\hline V & 70.9 & 44.3 & 108.6 & 1.2 \\
\hline $\mathrm{W} *$ & 3.4 & 3.5 & 3.9 & 1.7 \\
\hline $\mathrm{Y}$ & 29.9 & 48.7 & 31.5 & 1.4 \\
\hline $\mathrm{Yb}$ & 3.0 & 5.0 & 3.1 & 1.3 \\
\hline $\mathrm{Zn}$ & 66.9 & 34.5 & 105.4 & 0.9 \\
\hline $\mathrm{Zr}$ & 257.0 & 608.6 & 173.8 & 1.4 \\
\hline
\end{tabular}

${ }^{a}$ Integrated sediment composition was obtained using the modeled suspended load chemical composition and bed load chemical composition. Bed load: average of all bed load samples chemical composition. Ganga surface sediments: chemical composition all surface samples of Ganga. Integrated sediment/ UCC: Ganga modeled total sediments chemical composition normalized to the upper continental crust of Taylor and McLennan [1985, 1995]. Details and uncertainty are reported in Table S5. Elements for which no relation with grain size was found and that could not be modeled are marked by an asterisk; the estimate of average composition is derived from the average of all available data. 


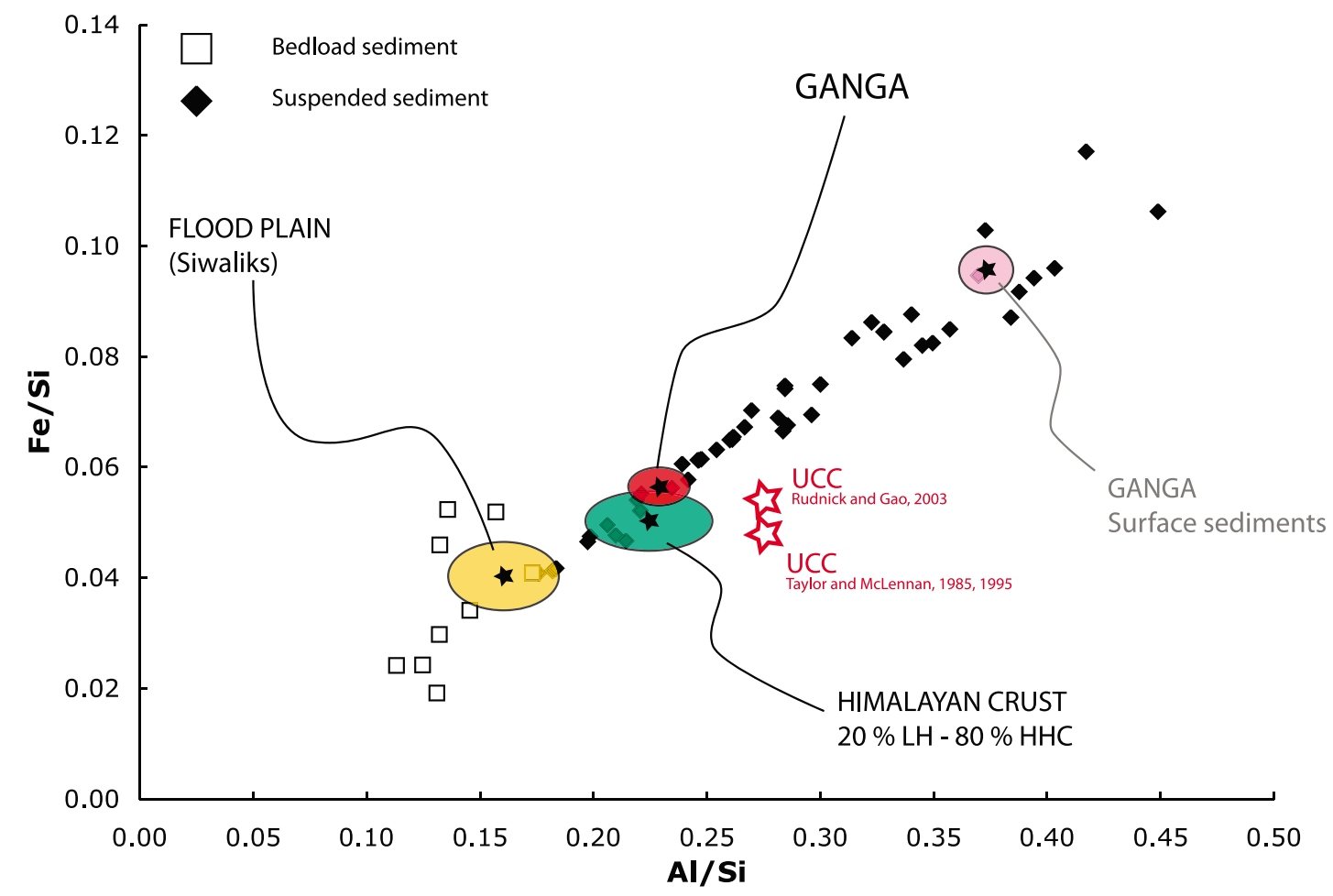

Figure 15. $\mathrm{Al} / \mathrm{Si}$ versus $\mathrm{Fe} / \mathrm{Si}$ for the Ganga sediments as modeled in this work, Siwaliks as modern floodplain sediments analogs, Himalayan crust from Galy and France-Lanord [2001] and Ganga surface sediments for comparison (molar ratios). Individual sampled suspended sediments and dredged bed load samples are plotted as black diamonds and open squares respectively. Also plotted is the Upper Continental Crust (UCC) as defined by Taylor and McLennan [1985, 1995] and Rudnick and Gao [2003].

contemporaneous Himalayan erosion rates $(1-3 \mathrm{~mm} / \mathrm{yr})$ derived from different methods and studies [e.g., Brunsden et al., 1981; Delcaillau, 1992; Sinha and Friend, 1994; Lavé and Avouac, 2001; Burbank et al., 2003; Vance et al., 2003; Garzanti et al., 2007; Gabet et al., 2008] but, unlike other studies, it represents an integration of Himalayan erosion over a broad segment of the Himalayan range.

\section{Conclusion}

[55] Large rivers are often studied for their ability to deliver an integrated signal of the surface processes operating in their basin. Nevertheless, the interpretation and use of the sediment signal is often hampered by the spatial and temporal variability observed within rivers. Better constraining the chemical composition of the exported sediments is a step toward a better understanding of the redistribution of elements across the earth's surface by allowing us to make continental scale chemical budgets. This work stresses the need to carefully address the chemical composition of sediments in large rivers to resolve basin scale processes. For this purpose, samplings limited to surface sediments are not representative of the integrated flux and should be used with caution, as they are likely systematically biased.

[56] In the Ganga River, the sediment concentration profiles are well explained by a Rouse type equation, which allows us to estimate the instantaneous sediment flux and average grain size of a river water column. These parameters are correlated to the local hydraulic energy of the flow expressed as the bottom shear velocity. This empirical relation is used to further extrapolate sediment fluxes and grain size laterally across the river channel and finally, using the recorded hydrograph, over the whole hydrological year. Ganga sediments chemical compositions are strongly correlated to the grain size parameter $D_{84}$ that was determined from the integrated fluxes. Using the model output the estimated flux of $\mathrm{Si}, \mathrm{Al}$ and $\mathrm{Fe}$ to the oceans is respectively $4.4 \cdot 10^{12}, 9.6 \cdot 10^{11}$ and $2.4 \cdot 10^{11} \mathrm{~mol} / \mathrm{yr}$ for the Ganga. The total modeled solid flux of ca. $400 \mathrm{Mt} / \mathrm{yr}$ is in agreement with previous studies. While the sediment flux calculated using this approach appears to be realistic, the calculated chemical composition is much more silica rich than previously reported for suspended sediment of the Ganga. This is due to the fact that high concentrations of coarse, siliceous material are carried in the deeper layers, which is generally not documented in large rivers.

[57] The comparison of the Ganga sediment chemistry with Himalayan crust and floodplain chemical composition end-members shows that approximately $10 \%$ of the initial sediments produced by Himalayan erosion are currently deposited in the plain. The Ganga basin is thus largely bypassed by the Himalayan sediments and the limited difference between the chemical composition of Ganga sediments and the Himalayan crust is evidence that the floodplain does not have a major influence on the exported sediments in terms of immobile elements even though this may have been varying during the Quaternary as a response to strong climate shifts. 


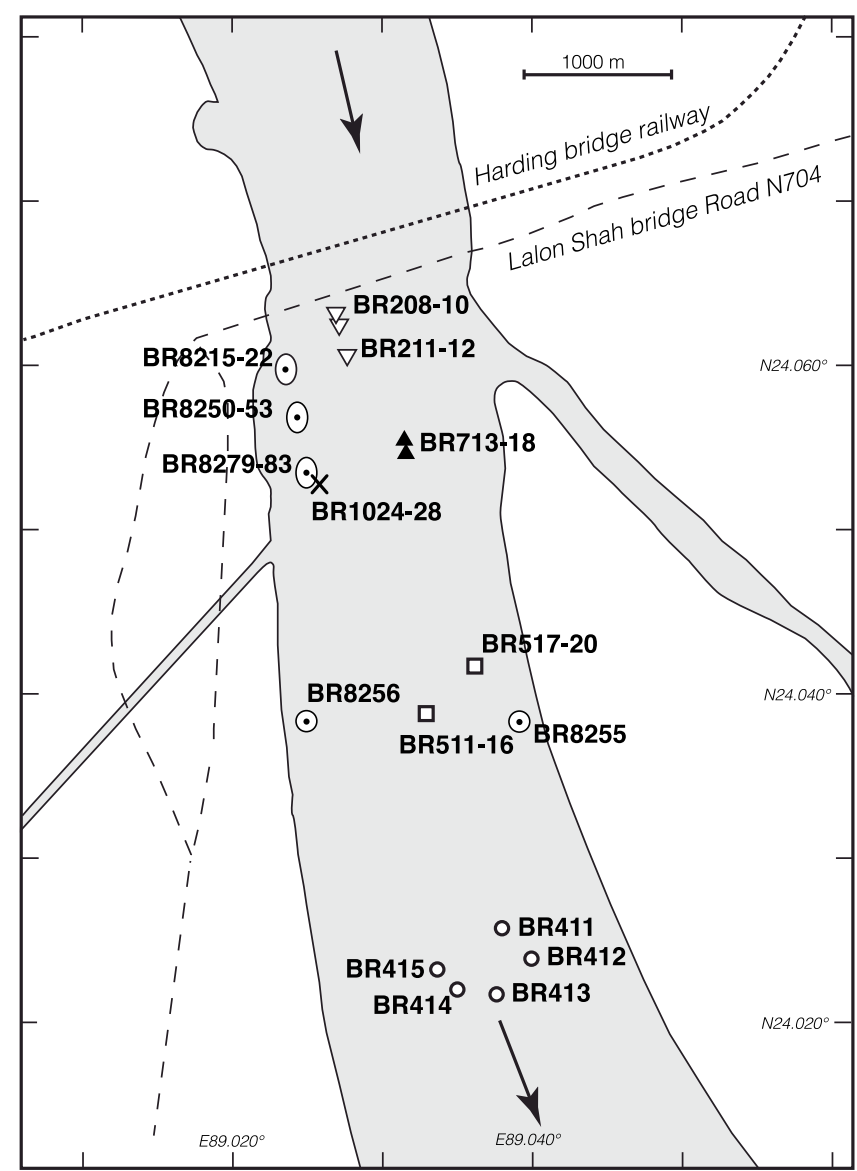

Figure A1. Detailed map of sample location, downstream of Harding Bridge on the Ganga.

\section{Appendix A: Sample Location}

[58] Samples were collected using a horizontal sampler that was lowered at the desired depth from local boats. For each sample in a depth profile, the boat was repositioned at its original location and sampling was performed while drifting at the river water velocity. The sample location is shown in Figure A1.

\section{Appendix B: Grain Size-Friction Velocity Relation}

[59] Average $D_{84}$ of Ganga sediments was computed from the spatially and temporally extrapolated sediment flux in every grain size class. This extrapolation was based on the relation between total sediment flux in grain size $q_{s}^{i}$ and local shear velocity $u^{*}$. Figure B1 shows the fitted power law parameters for each grain size class. The grain size classes 255-305 $\mu \mathrm{m}, 305-365 \mu \mathrm{m}$ and 365-435 $\mu \mathrm{m}$ were stacked in a single $255-435 \mu \mathrm{m}$ size class for more robust calculations in the large grain size classes. This does not affect $D_{84}$ calculations as $D_{84}<255 \mu \mathrm{m}$.

\section{Appendix C: Moving Bed Bias and Fluxes}

[60] ADCP measurements detected the occurrence of moving bed for average water column velocities of $1.1 \mathrm{~m} / \mathrm{s}$
(Figure 3) and a threshold in the shear velocity of $u^{*}>0.03$ $0.04 \mathrm{~m} / \mathrm{s}$ (or $\tau_{0}=0.9-1.3 \mathrm{~N} / \mathrm{m}^{2}$, Figure $\mathrm{C} 1$ ). This is significantly higher than the threshold for bed sediment motion that marks the onset of saltation bed load transport. For sediments of $220 \mu \mathrm{m}$ diameter (average $D_{50}$ of Ganga bed load) critical shear stress for initiation of motion using a Shields diagram is $\tau_{c}=0.16 \mathrm{~N} / \mathrm{m}^{2}\left(u_{c}{ }^{*}=0.013 \mathrm{~m} / \mathrm{s}\right)$ [Vanoni, 1964; Brownlie, 1981] meaning that bed sediments are already mobilized when moving bed is detected. The onset of a sheet flow bed load transport regime is proposed to occur for dimensionless shear stress, $\theta=\tau_{0} /\left[g \cdot\left(\rho_{s}-\rho\right) D_{50}\right]$, exceeding 0.6 to 1 (where $\tau_{0}$ is the bed shear stress, $g$ is the acceleration of gravity, $\rho_{s}=$ grain density, $\rho=$ fluid density and $D_{50}$ the median grain size) [Nnadi and Wilson, 1995; Sumer et al., 1996; Abrahams, 2003]. ADCP moving bed is detected before the occurrence of sheet flow, as $u^{*}=0.03-0.04 \mathrm{~m} / \mathrm{s}$ implies $\theta=0.24-0.44$, and suggests that for sand bed rivers the ADCP measurements are sensitive to bed load motion occurring as saltation.

[61] The literature reports a wealth of bed load flux formulas (see Garcia [2008] for a list). A large number of bed load fluxes can be expressed as dimensionless bed load transport rate $\left(q^{*}\right)$ that can be related to a volumetric bed load flux $\left(q_{b}^{v}\right)$ through:

$$
q^{*}=\frac{q_{b}^{v}}{D \sqrt{g R D}}
$$

To complete and compare the fluxes calculated by van Rijn [1984a, 1993, 2007] (equation (8)), we used three other formulations of bed load transport. First, a reformulation of the Meyer-Peter and Muller [1948] relation, originally developed for coarse sand and gravel bed streams but widely used in sand bed streams (equation (C2)); second, an empirical relation from Wilson [1966] derived for high bed load transport rates (equation (C3)); and third, a relation from Cheng [2002] that does not rely on the critical shear stress notion (equation (C3)):

$$
\begin{gathered}
q^{*}=3.97 \cdot\left(\tau^{*}-0.0495\right)^{3 / 2} \\
q^{*}=12 \cdot\left(\tau^{*}-\tau_{c r}\right)^{3 / 2} \\
q^{*}=13 \cdot \tau^{* 3 / 2} \cdot \exp \left(\frac{-0.05}{\tau^{* 3 / 2}}\right)
\end{gathered}
$$

where the dimensionless shear stress $\tau^{*}=\tau / \rho g R D$ with $g$ the acceleration of gravity, $R=\left(\rho_{s}-\rho\right) / \rho$ the submerged specific gravity of the sediment, $\rho_{s}$ and $\rho$ the sediment and water density, $D$ the grain-size of the considered material (here the average $D_{50}$ of all available bed loads) and $\tau_{c r}{ }^{*}$ is determined from the Shields diagram. Instantaneous bed load fluxes for the available water column profiles were calculated and results can be found in Table $\mathrm{C} 1$. All bed load flux relation predict fluxes that are of the same order of magnitude as the relation of van Rijn [1984a, 1993, 2007], equation (10), used in this work. Equation $(\mathrm{C} 4)$ yields the highest bed load fluxes with up to $1.6 \mathrm{~kg} / \mathrm{m} / \mathrm{s}$ for profile $17 / 09 / 2007$, which is ca. 2.5 times higher than the van Rijn relation. All relations agree on the fact that bed load flux represents less than $5 \%$ of the suspended load flux. 

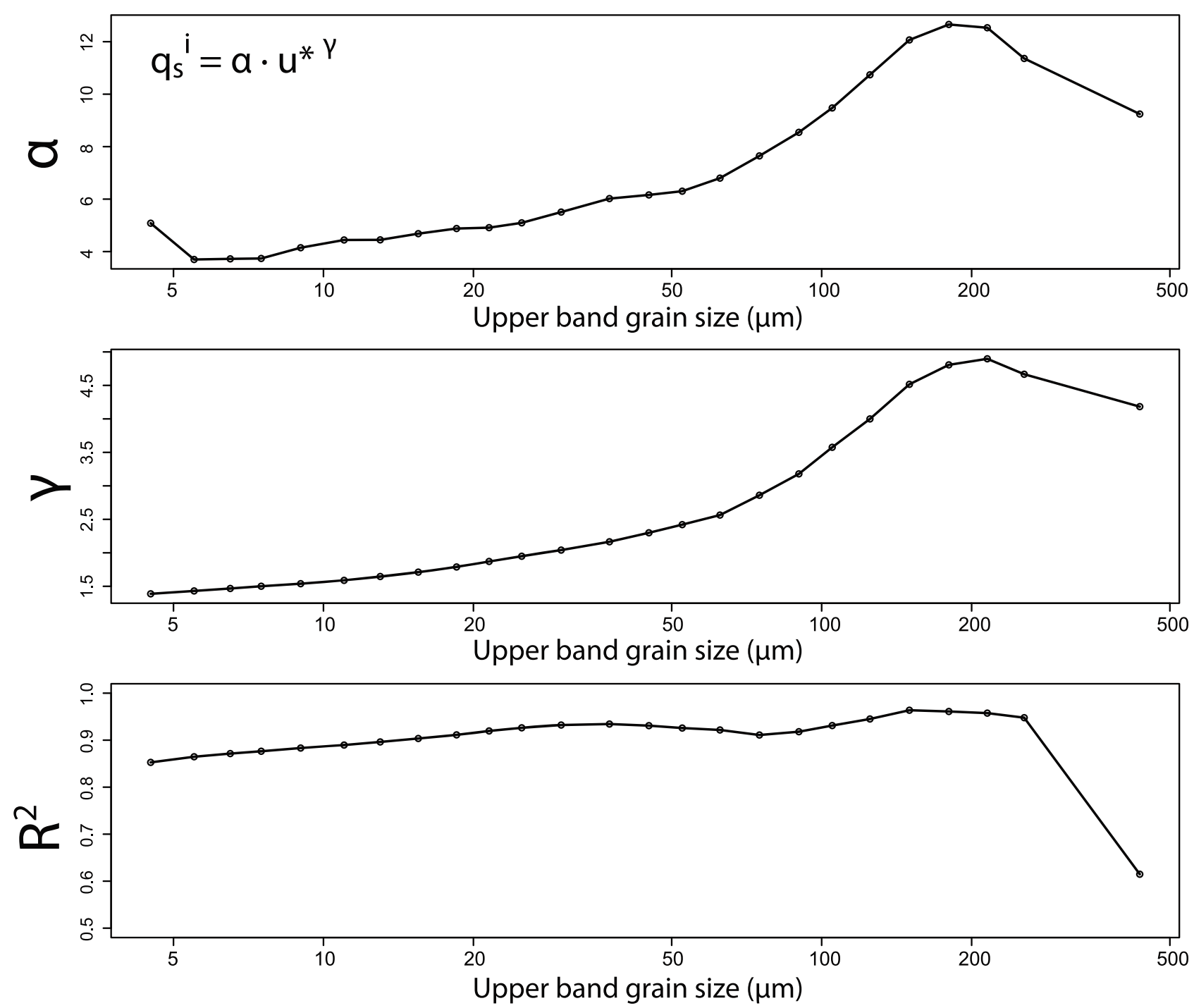

Figure B1. Regression parameters $\alpha$ and $\gamma$ obtained from fitting instantaneous sediment fluxes in every grain size class $\left(q_{s}^{i}\right)$ as a function of $u^{*}$ and associated $\mathrm{R}^{2}$ regression statistic. $\alpha$ and $\gamma$ were used to predict $q_{s}^{i}$ from $u^{*}$ for both spatial and temporal extrapolation of sediment flux and grain size.

[62] Spatial and temporal extrapolation of the bed load flux across the channel and during the hydrological cycle yields 3 $\mathrm{Mt} / \mathrm{yr}$ for (C2), $10 \mathrm{Mt} / \mathrm{yr}$ for (C3) and $9 \mathrm{Mt} / \mathrm{yr}$ for (C4) which should be compared to the $4 \mathrm{Mt} / \mathrm{yr}$ flux derived from the van Rijn relation (10) and the modeled $390 \mathrm{Mt} / \mathrm{yr}$ of suspendedload flux.

\section{Appendix D: Geochemical Budget}

[63] The chemical budget (12) can be written for all three immobile elements $\mathrm{Si}, \mathrm{Al}$ and $\mathrm{Fe}$. Combining these equations for $\mathrm{Si}$ and $\mathrm{Al}$ on one hand and $\mathrm{Si}$ and $\mathrm{Fe}$ on the other hand to eliminate $\Phi_{\text {Him }}$, yields (D1) and (D2) and two estimates of $\Phi_{\text {FloodP }}[$ Galy and France-Lanord, 2001]:

$$
\begin{gathered}
\phi_{\text {FloodP }}=\frac{\phi_{\text {Diss }} \cdot\left[\mathrm{SiO}_{2}\right]_{\text {Diss }}+\phi_{\text {IntSed }} \cdot\left(\left[\mathrm{SiO}_{2}\right]_{\text {IntSed }}-\left[\mathrm{Al}_{2} \mathrm{O}_{3}\right]_{\text {IntSed }} \cdot\left[\mathrm{SiO}_{2}\right]_{\mathrm{Him}} /\left[\mathrm{Al}_{2} \mathrm{O}_{3}\right]_{\mathrm{Him}}\right)}{\left[\mathrm{Al}_{2} \mathrm{O}_{3}\right]_{\text {FloodP }} \cdot\left[\mathrm{SiO}_{2}\right]_{\mathrm{Him}} /\left[\mathrm{Al}_{2} \mathrm{O}_{3}\right]_{\mathrm{Him}}-[\mathrm{SiO}]_{\mathrm{FloodP}}} \\
\phi_{\text {FloodP }}=\frac{\phi_{\text {Diss }} \cdot\left[\mathrm{SiO}_{2}\right]_{\text {Diss }}+\phi_{\text {IntSed }} \cdot\left(\left[\mathrm{SiO}_{2}\right]_{\text {IntSed }}-2\left[\mathrm{Fe}_{2} \mathrm{O}_{3}\right]_{\text {IntSed }} \cdot\left[\mathrm{SiO}_{2}\right]_{\mathrm{Him}} /\left[\mathrm{Fe}_{2} \mathrm{O}_{3}\right]_{\mathrm{Him}}\right)}{\left[\mathrm{Fe}_{2} \mathrm{O}_{3}\right]_{\text {FloodP }} \cdot\left[\mathrm{SiO}_{2}\right]_{\mathrm{Him}} /\left[\mathrm{Fe}_{2} \mathrm{O}_{3}\right]_{\mathrm{Him}}-\left[\mathrm{SiO}_{2}\right]_{\mathrm{FloodP}}}
\end{gathered}
$$




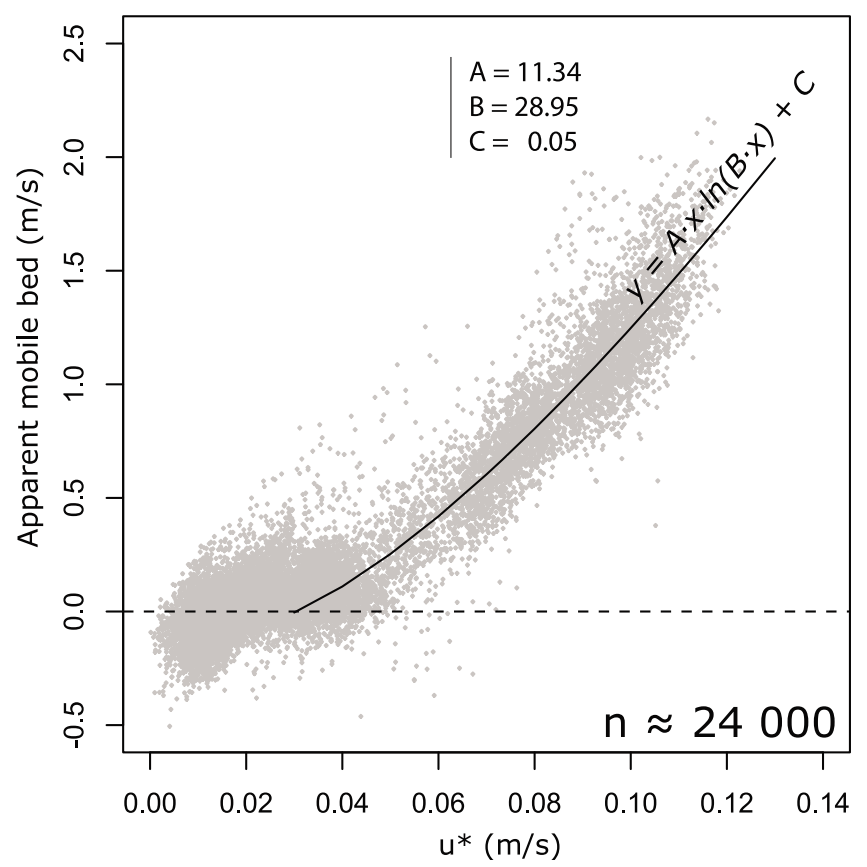

Figure C1. Apparent moving bed velocity (computed by the difference between GPS and BT reference water velocity measurements) as a function of shear velocity $\left(u^{*}\right)$. Moving bed conditions are encountered for $u^{*}>0.03-0.04 \mathrm{~m} / \mathrm{s}$.

This calculation relies on $\mathrm{SiO}_{2}, \mathrm{Al}_{2} \mathrm{O}_{3}$ and $\mathrm{Fe}_{2} \mathrm{O}_{3}$ concentrations in the Ganga sediments, and in the floodplain. It only requires the $\left[\mathrm{SiO}_{2}\right] /\left[\mathrm{Al}_{2} \mathrm{O}_{3}\right]$ and $\left[\mathrm{SiO}_{2}\right] /\left[\mathrm{Fe}_{2} \mathrm{O}_{3}\right]$ ratios of the Himalayan crust which has the advantage of being independent of carbonate content of source rocks which are difficult to estimate for the whole Himalayan arc. The endmember compositions used for the calculation are given in Table D1.

[64] Solving (D1) and (D2) for $\Phi_{\text {FloodP }}$ yields respectively: $3.9( \pm 136)$ Mt and $123( \pm 177)$ Mt of stored sediments with the Siwaliks and the Himalayan crust composition as endmembers. Combining both estimates and uncertainties yields an estimate of total sequestration of $43 \mathrm{Mt}( \pm 97)$, which represents $10 \%$ of the total Himalayan erosion flux.

Table C1. Instantaneous Bed Load Fluxes $\left(q_{b}\right)$ and Ratio of Suspended $\left(q_{s}\right)$ to Bed Load Flux in Percent

\begin{tabular}{lccccccc}
\hline $\begin{array}{c}\text { Sampling } \\
\text { Date }\end{array}$ & $\tau^{*}$ & $\begin{array}{c}q_{b}{ }^{\mathrm{a}} \\
(\mathrm{kg} / \mathrm{m} / \mathrm{s})\end{array}$ & $\begin{array}{c}q_{b} / q_{s}{ }^{\mathrm{a}} \\
(\%)\end{array}$ & $\begin{array}{c}q_{b}{ }^{\mathrm{b}} \\
(\mathrm{kg} / \mathrm{m} / \mathrm{s})\end{array}$ & $\begin{array}{c}q_{b} / q_{s}{ }^{\mathrm{b}} \\
(\%)\end{array}$ & $\begin{array}{c}q_{b}{ }^{\mathrm{c}} \\
(\mathrm{kg} / \mathrm{m} / \mathrm{s})\end{array}$ & $\begin{array}{c}q_{b} / q_{s}{ }^{\mathrm{c}} \\
(\%)\end{array}$ \\
\hline $13 / 08 / 2010$ & 0.079 & 0.001 & 0.08 & 0.003 & 0.33 & 0.001 & 0.12 \\
$01 / 09 / 08$ & 1.374 & 0.218 & 0.59 & 0.663 & 1.80 & 0.730 & 1.98 \\
$10 / 09 / 08$ & 1.413 & 0.227 & 0.84 & 0.692 & 2.55 & 0.763 & 2.80 \\
$22 / 09 / 08$ & 0.353 & 0.024 & 0.30 & 0.075 & 0.92 & 0.077 & 0.96 \\
$17 / 09 / 07$ & 2.307 & 0.484 & 1.11 & 1.471 & 3.38 & 1.616 & 3.71 \\
$23 / 07 / 05 \mathrm{a}$ & 1.374 & 0.218 & 0.76 & 0.663 & 2.30 & 0.730 & 2.53 \\
$23 / 07 / 05 \mathrm{~b}$ & 0.315 & 0.020 & 0.19 & 0.061 & 0.61 & 0.062 & 0.62 \\
$13 / 08 / 04$ & 1.082 & 0.150 & 0.75 & 0.457 & 2.29 & 0.503 & 2.52
\end{tabular}

${ }^{\mathrm{a}}$ Calculation was made using (a) a reformulation [Wong and Parker, 2006] of the Meyer-Peter and Muller [1948], equation (C2).

${ }^{\mathrm{b}}$ Calculation was made using Wilson [1966], equation (C3).

${ }^{\mathrm{c}}$ Calculation was made using Cheng [2002], equation (C4).
Table D1. Chemical Composition of the Reservoirs Used for Solving the Chemical Mass Balance of Himalayan Erosion Fluxes ${ }^{\mathrm{a}}$

\begin{tabular}{lccc}
\hline \hline \multicolumn{1}{c}{ Reservoir } & $\mathrm{SiO}_{2}(\mathrm{wt} \%)$ & $\mathrm{Al}_{2} \mathrm{O}_{3}(\mathrm{wt} \%)$ & $\mathrm{Fe}_{2} \mathrm{O}_{3}(\mathrm{wt} \%)$ \\
\hline Ganga (Ssed) & $65.29( \pm 0.81)$ & $12.35( \pm 0.40)$ & $4.77( \pm 0.19)$ \\
Siwaliks (FloodP) & $64.47( \pm 3.31)$ & $7.73( \pm 0.98)$ & $3.03( \pm 0.39)$ \\
Ganga plain BL & $74.12( \pm 4.18)$ & $9.33( \pm 1.25)$ & $3.32( \pm 0.64)$ \\
\hline & $\mathrm{SiO}_{2} / \mathrm{Al}_{2} \mathrm{O}_{3}$ & $\mathrm{SiO}_{2} / \mathrm{Fe}_{2} \mathrm{O}_{3}$ & \\
& $(\mathrm{wt} \%)$ & $(\mathrm{wt} \%)$ & \\
\hline Himalayan crust (Him) & $5.31( \pm 0.66)$ & $14.93( \pm 0.11)$ & \\
Himalayan front rivers & $5.4( \pm 0.54)$ & $15.46( \pm 1.54)$ & \\
\hline \hline
\end{tabular}

${ }^{\mathrm{a}}$ The Ganga sediment compositions are from this study. The composition of the Siwaliks as analog for floodplain sediments is based on 72 samples from the Suraï and Karnali sections (Table S7). Ganga floodplain sediments are also given for comparison and reported in Table S8. The Himalayan source rock composition is from Galy and France-Lanord [2001] and is comparable to Himalayan rivers sampled at the Himalayan front (Table S6).

[65] Even if the absolute concentration of $\mathrm{SiO}_{2}, \mathrm{Al}_{2} \mathrm{O}_{3}$ and $\mathrm{Fe}_{2} \mathrm{O}_{3}$ in both floodplain end-members, the Siwaliks and the Ganga plain bed loads, is different due to variable carbonate content, the $\mathrm{Al} / \mathrm{Si}$ and $\mathrm{Fe} / \mathrm{Si}$ ratios are identical. The use of Ganga plain bed load sediments as floodplain end-member yields similar results within uncertainty (45 $\pm 88 \mathrm{Mt}$ ) compared to the Siwaliks end-member used above. Similarly the chemical composition of the Himalayan crust and Himalayan-front Rivers is very similar and has only a minor influence on the sequestration flux computed from (D1) and (D2) $(68 \pm 78 \mathrm{Mt})$. This stability gives us confidence in the values used as end-members.

[66] Acknowledgments. The authors are greatly indebted to Mustafizur Rahman of Dhaka University, who provided great support and help during field campaigns in Bangladesh. We also thank Estelle Blaes, Marion Garçon, and Britta Voss for their enthusiastic help with sampling and ADCP data acquisition. We would also like to thank Rolf Aalto, three other anonymous reviewers, and the Editor for their comments that helped to improve the quality and readability of the manuscript. This work was supported by INSU program "Relief de la Terre" and ANR Calimero. Valier Galy was supported by the U.S. National Science Foundation (grant OCE-0851015).

\section{References}

Abdel-Fattah, S., A. Amin, and L. C. van Rijn (2004), Sand transport in Nile River, Egypt, J. Hydraul. Eng., 130, 488-500, doi:10.1061/ (ASCE)0733-9429(2004)130:6(488).

Abrahams, A. D. (2003), Bed-load transport equation for sheet flow, J. Hydraul. Eng., 129, 159-163, doi:10.1061/(ASCE)0733-9429(2003) 129:2(159)

Ahmed, R., and S. Karmakar (1993), Arrival and withdrawal dates of the summer monsoon in Bangladesh, Int. J. Climatol., 13, 727-740, doi:10.1002/joc.3370130703.

Avouac, J. P., and E. B. Burov (1996), Erosion as a driving mechanism of intracontinental mountain growth, J. Geophys. Res., 101, 17,747-17,769, doi:10.1029/96JB01344.

Bangladesh Water Development Board (1972), Sediment investigations in main rivers of Bangladesh, Water Suppl. Pap. 359, Dhaka.

Beaumont, C., R. A. Jamieson, M. H. Nguyen, and B. Lee (2001), Himalayan tectonics explained by extrusion of a low-viscosity crustal channel coupled to focused surface denudation, Nature, 414, 738-742, doi:10.1038/414738a.

Bennett, S., J. Bridge, and J. Best (1998), Fluid and sediment dynamics of upper stage plane beds, J. Geophys. Res., 103, 1239-1274, doi:10.1029/ 97JC02764.

Bouchez, J., O. Beyssac, V. Galy, J. Gaillardet, C. France-Lanord, L. Maurice, and P. Moreira-Turcq (2010), Oxidation of petrogenic organic carbon in the Amazon floodplain as a source of atmospheric $\mathrm{CO}_{2}$, Geology, 38, 255-258, doi:10.1130/G30608.1.

Bouchez, J., J. Gaillardet, C. France-Lanord, L. Maurice, and P. Dutra-Maia (2011a), Grain size control of river suspended sediment geochemistry: 
Clues from Amazon River depth profiles, Geochem. Geophys. Geosyst., 12, Q03008, doi:10.1029/2010GC003380.

Bouchez, J., F. Metivier, M. Lupker, L. Maurice, M. Perez, J. Gaillardet, and C. France-Lanord (2011b), Prediction of depth-integrated fluxes of suspended sediment in the Amazon River: Particle aggregation as a complicating factor, Hydrol. Processes, 25, 778-794, doi:10.1002/hyp.7868.

Bouchez, J., M. Lupker, J. Gaillardet, L. Maurice, and C. France-Lanord (2011c), How important is it to integrate riverine suspended sediment chemical composition with depth? Clues from Amazon River depthprofiles, Geochim. Cosmochim. Acta, in press.

Brownlie, W. R. (1981), Prediction of flow depth and sediment discharge in open channels, Rep. KH-R-43A, W. M. Keck Lab. of Hydraul. and Water Resour., Calif. Inst. of Technol., Pasadena.

Brunsden, D., D. K. C. Jones, R. P. Martin, and J. C. Doornkamp (1981), The geomorphological character of part of the Low Himalaya of eastern Nepal, Z. Geomorphol., Suppl., 37, 25-72.

Burbank, D., A. Blythe, J. Putkonen, B. Pratt-Sitaula, E. Gabet, M. Oskin, A. Barros, and T. Ojha (2003), Decoupling of erosion and precipitation in the Himalayas, Nature, 426, 652-655, doi:10.1038/nature02187.

Callède, J., P. Kosuth, J.-L. Guyot, and V. S. Guimaraes (2000), Discharge determination by acoustic Doppler current profilers (ADCP): A moving bottom error correction method and its application on the River Amazon at Obidos, Hydrol. Sci. J., 45, 911-924, doi:10.1080/ 02626660009492392 .

Carignan, J., P. Hild, G. Mevelle, J. Morel, and D. Yeghicheyan (2001), Routine analyses of trace elements in geological samples using flow injection and low pressure on-line liquid chromatography coupled to ICP-MS: A study of geochemical reference materials BR, DR-N, UB-N, AN-G and GH, Geostand. Newsl., 25, 187-198, doi:10.1111/j.1751908X.2001.tb00595.x.

Cellino, M., and W. H. Graf (1999), Sediment-laden flow in open-channels under noncapacity and capacity conditions, J. Hydraul. Eng., 125, 455-462, doi:10.1061/(ASCE)0733-9429(1999)125:5(455).

Chandra, S., E. Rhodes, and K. Richards (2007), Luminescence dating of late Quaternary fluvial sediments in the Rapti Basin, north-central Gangetic plains, Quat. Int., 159, 47-56, doi:10.1016/j.quaint.2006.08.011.

Cheng, N. (2002), Exponential formula for bedload transport, J. Hydraul. Eng., 128, 942-946, doi:10.1061/(ASCE)0733-9429(2002)128:10(942).

China-Bangladesh Joint Expert Team (1991), Study report on flood control and river training project on the Brahmaputra River in Bangladesh, report, Dhaka.

Coleman, M. L. (1970), Flume studies of sediment transfer coefficient, Water Resour. Res., 6, 801-809, doi:10.1029/WR006i003p00801.

Curtis, W. F., R. H. Meade, C. F. Nordin, N. B. Price, and E. R. Sholkovitz (1979), Non uniform vertical distribution of fine sediment in the Amazon River, Nature, 280, 381-383, doi:10.1038/280381a0.

Delcaillau, B. (1992), Les Siwalik de l'Himalaya du Népal Oriental: Fonctionnement et Évolution d'un Piémont, Ed. du CNRS, Paris.

Delft Hydraulics and Danish Hydraulics Institute (1996), River Survey Project, Flood Action Plan 24, Water Resour. Plann. Org., Dhaka.

Dietrich, W. (1982), Settling velocity of natural particles, Water Resour Res., 18, 1615-1626, doi:10.1029/WR018i006p01615.

Droppo, I. G., and E. D. Ongley (1994), Flocculation of suspended sediment in rivers of southeastern Canada, Water Res., 28, 1799-1809, doi:10.1016/0043-1354(94)90253-4.

Edmond, J. M. (1992), Himalayan tectonics, weathering processes, and the strontium isotope record in marine limestones, Science, 258, 1594-1597, doi:10.1126/science.258.5088.1594.

Filizola, N., and J. L. Guyot (2004), The use of Doppler technology for suspended sediment discharge determinations on the River Amazon at Óbidos, Hydrol. Sci. J., 49, 143-153, doi:10.1623/hysj.49.1.143.53990.

Food and Agriculture Organization of the United Nations (FAO) (1971), Soil survey project, Bangladesh: Soil resources, $A G L: S F / P A K$ 6, Tech. Rep. 3, 211 pp., Rome.

France-Lanord, C., and L. Derry (1997), Organic carbon burial forcing of the carbon cycle from Himalayan erosion, Nature, 390, 65-67, doi:10.1038/36324.

French Engineering Consortium (1989), Pre-Feasibility Study for Flood Control in Bangladesh, vol. 2, Present Conditions, Paris.

Gabet, E. J., D. W. Burbank, B. Pratt-Sitaula, J. Putkonen, and B. Bookhagen (2008), Modern erosion rates in the High Himalayas of Nepal, Earth Planet. Sci. Lett., 267, 482-494, doi:10.1016/j.eps1.2007.11.059.

Gaeuman, D., and R. B. Jacobson (2006), Acoustic bed velocity and bed load dynamics in a large sand bed river, J. Geophys. Res., 111, F02005, doi:10.1029/2005JF000411.

Gaillardet, J., B. Dupré, C. J. Allègre, and P. Négrel (1997), Chemical and physical denudation in the Amazon River Basin, Chem. Geol., 142, 141-173, doi:10.1016/S0009-2541(97)00074-0.
Gaillardet, J., B. Dupré, and C. J. Allègre (1999), Geochemistry of large river suspended sediments: Silicate weathering or recycling tracer?, Geochim. Cosmochim. Acta, 63, 4037-4051, doi:10.1016/S0016-7037(99)00307-5.

Galy, A., and C. France-Lanord (1999), Weathering processes in the Ganges-Brahmaputra basin and the riverine alkalinity budget, Chem. Geol., 159, 31-60, doi:10.1016/S0009-2541(99)00033-9.

Galy, A., and C. France-Lanord (2001), Higher erosion rates in the Himalaya: Geochemical constraints on riverine fluxes, Geology, 29, 23-26, doi:10.1130/0091-7613(2001)029<0023:HERITH >2.0.CO;2.

Galy, A., C. France-Lanord, and L. A. Derry (1999), The strontium isotopic budget of Himalayan Rivers in Nepal and Bangladesh, Geochim. Cosmochim. Acta , 63, 1905-1925, doi:10.1016/S0016-7037(99)00081-2.

Galy, V., C. France-Lanord, O. Beyssac, P. Faure, H. Kudrass, and F. Palhol (2007), Efficient organic carbon burial in the Bengal fan sustained by the Himalayan erosional system, Nature, 450, 407-410, doi:10.1038/ nature06273.

Galy, V., O. Beyssac, C. France-Lanord, and T. Eglinton (2008a), Recycling of graphite during Himalayan erosion: A geological stabilisation of carbon in the crust, Science, 322, 943-945, doi:10.1126/science. 1161408

Galy, V., C. France-Lanord, and B. Lartiges (2008b), Loading and fate of particulate organic carbon from the Himalaya to the Ganga-Brahmaputra delta, Geochim. Cosmochim. Acta, 72, 1767-1787, doi:10.1016/j. gca.2008.01.027.

Gansser, A. (1964), Geology of the Himalayas, Interscience, London.

Garcia, M. H. (2008), Sediment transport and morphodynamics, in Sedimentation Engineering: Processes, Measurements, Modeling and Practice, edited by M. H. García, pp. 21-164, Am. Soc. of Civ. Eng., Reston, Va.

Garzanti, E., G. Vezzoli, S. Ando, J. Lave, M. Attal, C. France-Lanord, and P. DeCelles (2007), Quantifying sand provenance and erosion (Marsyandi River, Nepal Himalaya), Earth Planet. Sci. Lett., 258, 500-515, doi:10.1016/j.epsl.2007.04.010.

Garzanti, E., S. Ando, C. France-Lanord, G. Vezzoli, P. Censi, V. Galy, and Y. Najman (2010), Mineralogical and chemical variability of fluvia sediments: 1. Bedload sand (Ganga-Brahmaputra, Bangladesh), Earth Planet. Sci. Lett., 299, 368-381, doi:10.1016/j.eps1.2010.09.017.

Garzanti, E., S. Andó, C. France-Lanord, P. Censi, P. Vignola, V. Galy, and M. Lupker (2011), Mineralogical and chemical variability of fluvial sediments: 2. Suspended-load silt (Ganga-Brahmaputra, Bangladesh), Earth Planet. Sci. Lett., 302, 107-120, doi:10.1016/j.eps1.2010.11.043.

Gaweesh, M. T. K., and L. C. van Rijn (1994), Bedload sampling in sandbed rivers, J. Hydraul. Eng., 120, 1364-1384, doi:10.1061/(ASCE)07339429(1994)120:12(1364).

Gislason, S. R., E. H. Oelkers, and A. Snorrason (2006), Role of riversuspended material in the global carbon cycle, Geology, 34, 49-52, doi:10.1130/G22045.1.

Goldstein, S. J., and S. B. Jacobsen (1988), Nd and Sr isotopic systematics of river-water suspended material: Implications for crustal evolution, Earth Planet. Sci. Lett., 87, 249-265, doi:10.1016/0012-821X(88) 90013-1.

Govindaraju, K., and G. Mevelle (1987), Fully automated dissolution and separation methods for inductively coupled plasma atomic emissionspectrometry rock analysis - application to the determination of rareearth elements, J. Anal. At. Spectrom., 2, 615-621, doi:10.1039 ja9870200615.

Graf, W., and M. Cellino (2002), Suspension flows in open channels; experimental study, J. Hydraul. Res., 40, 435-447, doi:10.1080/ 00221680209499886

Granet, M., F. Chabaux, P. Stille, A. Dosseto, C. France-Lanord, and E. Blaes (2010), U-series disequilibria in suspended river sediments and implication for sediment transfer time in alluvial plains: The case of the Himalayan rivers, Geochim. Cosmochim. Acta, 74, 2851-2865, doi:10.1016/j.gca. 2010.02.016.

Hodges, K., J. Hurtado, and K. Whipple (2001), Southward extrusion of Tibetan crust and its effect on Himalayan tectonics, Tectonics, 20 799-809, doi:10.1029/2001TC001281.

Holeman, J. N. (1968), The sediment yield of major river of the world, Water Resour. Res., 4, 737-747, doi:10.1029/WR004i004p00737.

Horowitz, A. J., and K. A. Elrick (1987), The relation of stream sediment surface area, grain size and composition to trace element chemistry, Appl. Geochem., 2, 437-451, doi:10.1016/0883-2927(87)90027-8.

Hossain, M. M. (1992), Total sediment load in the lower Ganges and Jammuna, J. Inst. Eng. Bangladesh, 20(1-2), 1-8.

Islam, G. M. T., and S. T. Jaman (2006), Modeling sediment loads in the lower Ganges, Bangladesh, Water Manage., 159, 87-94.

Islam, M. R., S. F. Begum, Y. Yamaguchi, and K. Ogawa (1999), The Ganges and Brahmaputra rivers in Bangladesh: Basin denudation and sedimentation, Hydrol. Process., 13, 2907-2923, doi:10.1002/(SICI) 1099-1085(19991215)13:17<2907::AID-HYP906>3.0.CO;2-E 
Jordan, P. R. (1965), Fluvial sediment of the Mississippi River at St. Louis, Missouri, U.S. Geol. Surv. Water Supply Pap., 1802, 89 pp.

Joshi, D. D., and S. P. Bhartiya (1991), Geomorphic history and lithostatigraphy of a part of eastern Gangetic plain. Uttar Pradesh, J. Geol. Soc. India, 37, 569-576.

Kostaschuk, R., J. Best, P. Villard, J. Peakall, and M. Franklin (2005), Measuring flow velocity and sediment transport with an acoustic Doppler current profiler, Geomorphology, 68, 25-37, doi:10.1016/j.geomorph. 2004.07.012.

Lavé, J., and J. P. Avouac (2001), Fluvial incision and tectonic uplift across the Himalayas of central Nepal, J. Geophys. Res., 106, 26,561-26,591, doi:10.1029/2001JB000359.

Le Fort, P. (1975), Himalaya: The collided range. Present knowledge of the continental arc, Am. J. Sci., 275, 1-44.

Lyon-Caen, H., and P. Molnar (1985), Gravity-anomalies, flexure of the Indian plate, and the structure, support and evolution of the Himalaya and Ganga basin, Tectonics, 4, 513-538, doi:10.1029/ TC004i006p00513.

Martin, J. M., and M. Meybeck (1979), Elemental mass-balance of material carried by major world rivers, Mar. Chem., 7, 173-206, doi:10.1016/ 0304-4203(79)90039-2.

Master Plan Organization (1987), Floods and storms, Tech. Rep. 11, MPOHARZA Eng., Dhaka.

Mazumder, B. S. (1994), Grain-size distribution in suspension from bed materials, Sedimentology, 41, 271-277, doi:10.1111/j.1365-3091.1994. tb01405.x.

Mazumder, B. S., and K. Ghoshal (2006), Velocity and concentration profiles in uniform sediment-laden flow, Appl. Math. Model., 30, 164-176, doi:10.1016/j.apm.2005.03.015.

Mazumder, B., R. Ray, and D. Dalal (2005), Size distributions of suspended particles in open channel flow over bed materials, Environmetrics, 16, 149-165, doi:10.1002/env.690.

McCave, I. N., I. R. Hall, and G. G. Bianchi (2006), Laser vs. settling velocity differences in silt grainsize measurements: Estimation of palaeocurrent vigour, Sedimentology, 53, 919-928, doi:10.1111/j.13653091.2006.00783.x.

McCrea, J. M. (1950), On the isotopic chemistry of carbonates and a palaeotemperature scale, J. Chem. Phys., 18, 849-857, doi:10.1063/ 1.1747785.

Métivier, F., Y. Gaudemer, P. Tapponier, and M. Klein (1999), Mass accumulation rates in Asia during the Cenozoic, Geophys. J. Int., 137, 280-318, doi:10.1046/j.1365-246X.1999.00802.x.

Meyer-Peter, E., and R. Muller (1948), Formulas for bedload transport, in Proceedings of the 2nd Meeting of the International Association of Hydraulic Structures Research, Stockholm, Sweden, pp. 39-64, Int. Assoc. Hydraul. Res., Delft, Netherlands.

Milliman, J. D., and R. H. Meade (1983), World-wide delivery of river sediment to the oceans, J. Geol., 1, 1-21, doi:10.1086/628741.

Mueller, D. S., and C. R. Wagner (2007), Correcting acoustic Doppler current profiler discharge measurements biased by sediment transport, J. Hydraul. Eng., 133, 1329-1336, doi:10.1061/(ASCE)0733-9429 (2007)133:12(1329).

Mukhopadhyay, S. K., H. Biswas, T. K. De, and T. K. Jana (2006), Fluxes of nutrients from the tropical River Hooghly at the land-ocean boundary of Sundarbans, NE Coast of Bay of Bengal, India, J. Mar. Syst., 62, 9-21, doi:10.1016/j.jmarsys.2006.03.004.

Muste, M., and V. C. Patel (1997), Velocity profiles for particles and liquid in open-channel flow with suspended sediment, J. Hydraul. Eng., 123, 742-751, doi:10.1061/(ASCE)0733-9429(1997)123:9(742).

Muste, M., K. Yu, and M. Spasojevic (2004), Practical aspects of ADCP data use for quantification of mean river flow characteristics; Part I: Moving-vessel measurements, Flow Meas. Instrum., 15, 1-16, doi:10.1016/j.flowmeasinst.2003.09.001.

Muste, M., K. Yu, I. Fujita, and R. Ettema (2005), Two-phase versus mixed-flow perspective on suspended sediment transport in turbulent channel flows, Water Resour. Res., 41, W10402, doi:10.1029/ 2004WR003595.

Nnadi, F. N., and K. C. Wilson (1995), Bed-load motion at high-shear stress: Dune washout and plane-bed flow, J. Hydraul. Eng., 121, 267-273, doi:10.1061/(ASCE)0733-9429(1995)121:3(267).

Nordin, C. F., and G. R. Dempster (1963), Vertical distribution of velocity and suspended sediment middle Rio Grande, New Mexico, U.S. Geol. Surv. Prof. Pap., 462-B, 20 pp.

Paul, M. (2008), Etude des isotopes de l'osmium dans les eaux souterraines du Bangladesh et les sédiments himalayens: Implications et rôle de l'érosion himalayenne sur le budget océanique de l'osmium, Ph.D. thesis, Inst. Natl. Polytech. de Lorraine, Nancy, France.

Phillips, J. M., and D. E. Walling (1995), An assessment of the effects of sample collection, storage and resuspension on the representativeness of measurements of effective particle-size distribution of fluvial suspended sediment, Water Res., 29, 2498-2508, doi:10.1016/0043-1354(95) 00087-2.

Rao, K. L. (1979), India's Water Wealth, Orient Longman, New Delhi.

Raymo, M. E., W. F. Ruddiman, and P. N. Froelich (1988), Influence of late Cenozoic mountain building on ocean geochemical cycles, Geology, 16, 649-653, doi:10.1130/0091-7613(1988)016<0649:IOLCMB > 2.3. $\mathrm{CO} ; 2$.

Rennie, C. D., and P. V. Villard (2004), Site specificity of bed load measurement using an acoustic Doppler current profiler, J. Geophys. Res. 109, F03003, doi:10.1029/2003JF000106.

Rennie, C. D., R. G. Millar, and M. A. Church (2002), Measurement of bed load velocity using an acoustic Doppler current profiler, J. Hydraul. Eng., 128, 473-483, doi:10.1061/(ASCE)0733-9429(2002)128:5(473).

Rouse, H. (1950), Engineering Hydraulics, Wiley, New York.

Rudnick, R. L., and S. Gao (2003), The composition of the continental crust, in The Crust, vol. 3, Treatise on Geochemistry, edited by H. D. Holland and K. K. Turekian, Elsevier-Pergamon, Amsterdam.

Scott, C. H., and H. D. Stephens (1966), Special sediment investigations: Mississippi River at St. Louis, Missouri, 1961-63, U.S. Geol. Surv. Water Supply Pap., 1819-J, 35 pp.

Sime, L. C., R. I. Ferguson, and M. Church (2007), Estimating shear stress from moving boat acoustic Doppler velocity measurements in a large gravel bed river, Water Resour. Res., 43, W03418, doi:10.1029/ 2006WR005069.

Simons, D. B., and E. V. Richardson (1966), Resistance to flow in alluvial channels, U.S. Geol. Surv. Prof. Pap., 422J, 61 pp.

Singh, S., and C. France-Lanord (2002), Tracing the distribution of erosion in the Brahmaputra watershed from isotopic compositions of stream sediments, Earth Planet. Sci. Lett., 202, 645-662, doi:10.1016/S0012-821X (02)00822-1.

Singh, A. K., S. I. Hasnain, and D. K. Banerjee (1999), Grain size and geochemical partitioning of heavy metals in sediments of the Damodar River - A tributary of the lower Ganga, India, Environ. Geol., 39, 90-98, doi: $10.1007 / \mathrm{s} 002540050439$

Singh, M., I. B. Singh, and G. Mueller (2007), Sediment characteristics and transportation dynamics of the Ganga River, Geomorphology, 86 144-175, doi:10.1016/j.geomorph.2006.08.011.

Singh, S. K., S. K. Rai, and S. Krishnaswami (2008), Sr and Nd isotopes in river sediments from the Ganga Basin: Sediment provenance and spatial variability in physical erosion, J. Geophys. Res., 113, F03006, doi:10.1029/2007JF000909.

Sinha, R. (1996), Channel avulsion and floodplain structure in the GandakKosi interfan, North Bihar plains, India, Z. Geomorphol., 103, 249-268.

Sinha, R., and P. F. Friend (1994), River systems and their sediment flux, Indo-Gangetic plains, northern Bihar, India, Sedimentology, 41, 825-845, doi:10.1111/j.1365-3091.1994.tb01426.x.

Sinha, R., S. K. Tandon, P. S. Gibling, P. S. Bhattacharjee, and A. S. Dasgupta (2005), Late Quaternary geology and alluvial stratigraphy of the Ganga basin, Himal. Geol., 26, 223-240.

Smith, J. D., and S. R. McLean (1977), Spatially averaged flow over a wavy surface, J. Geophys. Res., 82, 1735-1746, doi:10.1029 JC082i012p01735.

Sumer, B. M., A. Kozakiewicz, J. Fredsoe, and R. Deigaard (1996), Velocity and concentration profiles in sheet-flow layer of movable bed, J. Hydraul. Eng., 122, 549-558, doi:10.1061/(ASCE)0733-9429(1996)122:10(549).

Taylor, S. R., and S. M. McLennan (1985), The Continental Crust: Its Composition and Evolution, Blackwell, Oxford, U. K.

Taylor, S. R., and S. M. McLennan (1995), The geochemical evolution of the continental crust, Rev. Geophys., 33, 241-265, doi:10.1029/ 95RG00262.

Tripathi, J. K., P. Ghazanfari, V. Rajamani, and S. K. Tandon (2007), Geochemistry of sediments of the Ganges alluvial plains: Evidence of largescale sediment recycling, Quat. Int., 159, 119-130, doi:10.1016/j. quaint.2006.08.016.

Turowski, J. M., D. Rickenmann, and S. J. Dadson (2010), The partitioning of the total sediment load of a river into suspended load and bedload: A review of empirical data, Sedimentology, 57, 1126-1146, doi:10.1111/ j.1365-3091.2009.01140.x.

van Rijn, L. C. (1984a), Sediment transport part I: Bedload transport, J. Hydraul. Eng., 110, 1431-1456, doi:10.1061/(ASCE)0733-9429 (1984)110:10(1431).

van Rijn, L. C. (1984b), Sediment transport part II: Suspended load transport, J. Hydraul. Eng., 110, 1613-1641, doi:10.1061/(ASCE)0733-9429 (1984)110:11(1613).

van Rijn, L. C. (1993), Principles of sediment transport in rivers, estuaries and Coastal Seas, Aqua Publ., Blokzijl, Netherlands.

van Rijn, L. C. (2007), Unified view of sediment transport by currents and waves. I: Initiation of motion, bed roughness, and bed-load trans- 
port, J. Hydraul. Eng., 133, 649-667, doi:10.1061/(ASCE)0733-9429 (2007)133:6(649)

Vance, D., M. Bickle, S. Ivy-Ochs, and P. W. Kubik (2003), Erosion and exhumation in the Himalaya from cosmogenic isotope inventories of river sediments, Earth Planet. Sci. Lett., 206, 273-288, doi:10.1016/ S0012-821X(02)01102-0.

Vanoni, V. A. (1946), Transportation of suspended sediment by water, Trans. Am. Soc. Civ. Eng., 111, 67-102.

Vanoni, V. A. (1964). Measurements of critical shear stress for entraining fine sediments in a boundary layer, Rep. $K H-R-7$, W. M. Keck Lab. of Hydraul. and Water Resour., Calif. Inst. of Technol., Pasadena.

Vdović, N., J. Biscan, and M. Juracic (1991), Relationship between surfacearea and some chemical and physical properties of particulates: Study in the Northern Adriatic, Mar. Chem., 36, 317-328, doi:10.1016/S03044203(09)90069-X.

Viers, J., B. Dupré, and J. Gaillardet (2009), Chemical composition of suspended sediments in World Rivers: New insights from a new database Sci. Total Environ., 407, 853-868, doi:10.1016/j.scitotenv.2008.09.053.

Walling, D. E., and P. W. Moorehead (1989), The particle-size characteristics of fluvial suspended sediment: An overview, Hydrobiologia, 176-177, 125-149, doi:10.1007/BF00026549.

Whiting, P. J., and W. E. Dietrich (1990), Boundary shear-stress and roughness over mobile alluvial beds, J. Hydraul. Eng., 116, 1495-1511, doi:10.1061/(ASCE)0733-9429(1990)116:12(1495).

Wilcock, P. R. (1996), Estimating local bed shear stress from velocity observations, Water Resour. Res., 32, 3361-3366, doi:10.1029/ 96WR02277.
Willett, S. D. (1999), Orogeny and orography: The effects of erosion on the structure of mountain belts, J. Geophys. Res., 104, 28,957-28,981, doi:10.1029/1999JB900248.

Wilson, K. C. (1966), Bedload transport at high shear stresses, J. Hydraul. Div. Am. Soc. Civ. Eng., 113, 97-103, doi:10.1061/(ASCE)0733-9429 (1987)113:1(97).

Wong, M., and G. Parker (2006), Re-analysis and correction of bedload relation of Meyer-Peter and Muller using their own database, J. Hydraul. Eng., 132, 1159-1168, doi:10.1061/(ASCE)0733-9429(2006)132: 11(1159).

J. Bouchez, J. Gaillardet, and F. Métivier, IPG, 1 Rue Jussieu, F-75238 Paris, France.

C. France-Lanord, J. Lavé, and M. Lupker, CRPG-CNRS, 15 Rue Notre Dame des Pauvres, F-54501 Vandœuvre lès Nancy, France. (mlupker@ crpg.cnrs-nancy.fr)

V. Galy, Department of Marine Chemistry and Geochemistry, Woods Hole Oceanographic Institution, 360 Woods Hole Rd., Woods Hole, MA 02543, USA.

B. Lartiges, LEM, 15 Av. du Charmois, F-54500 Vandœuvre lès Nancy, France.

J.-L. Mugnier, ISTerre, 1381 Rue de la Piscine, F-38400 Saint-Martin D'Hères, France. 